\title{
The ATLAS Insertable B-Layer (IBL) Project
}

Javier Bilbao

On behalf of the ATLAS IBL collaboration

RESMDD 2012 


\section{Outline}

- Motivation

- IBL design

- Front-end and sensor technology

- Modules qualification after radiation

- First stave production and results

- Schedule 


\section{ATLAS and LHC program}

\section{Actual Inner detector}

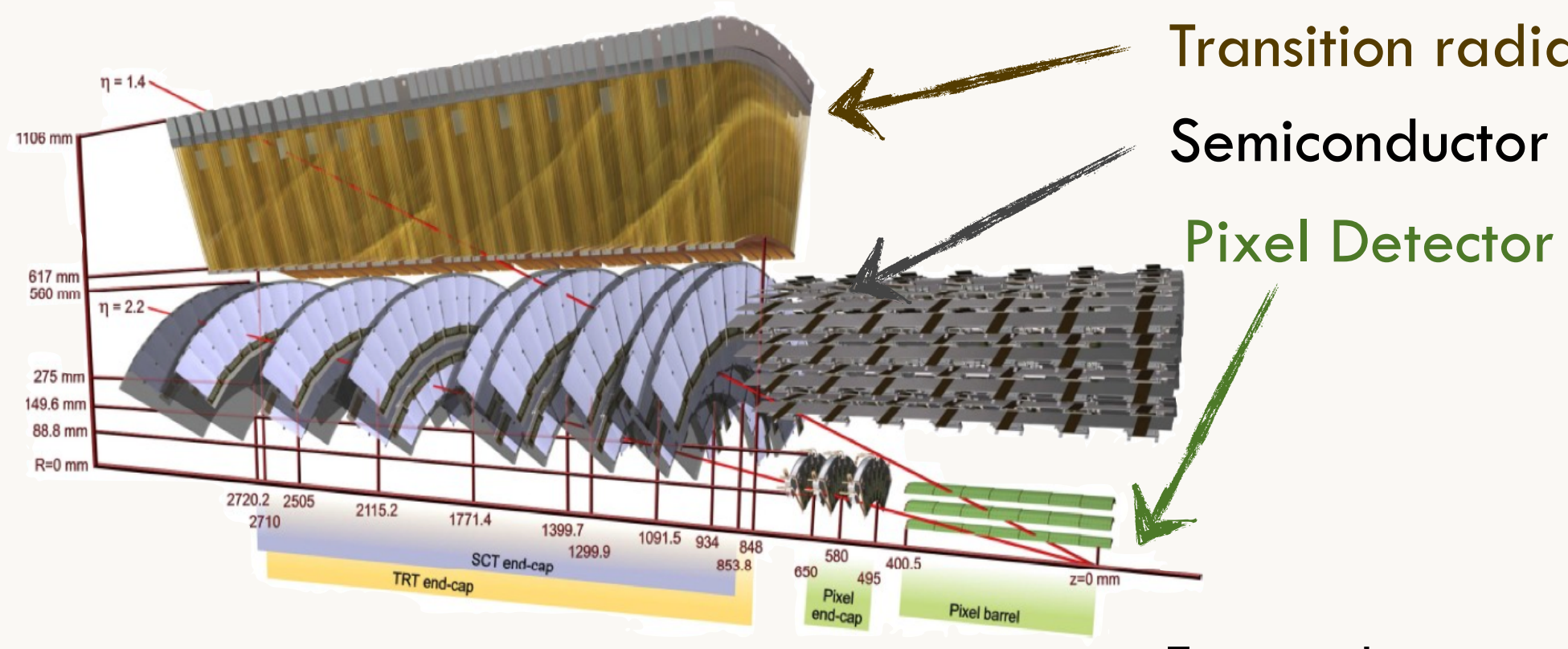

Operating since 2009 with an integrated luminosity $\leq 30 \mathrm{fb}^{-1}$

ront-end and sensor technology

Modules qualification after radiation

First stave production and results

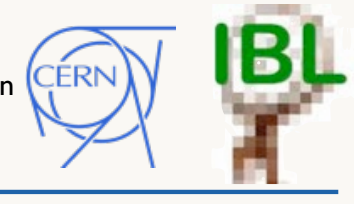

Expected

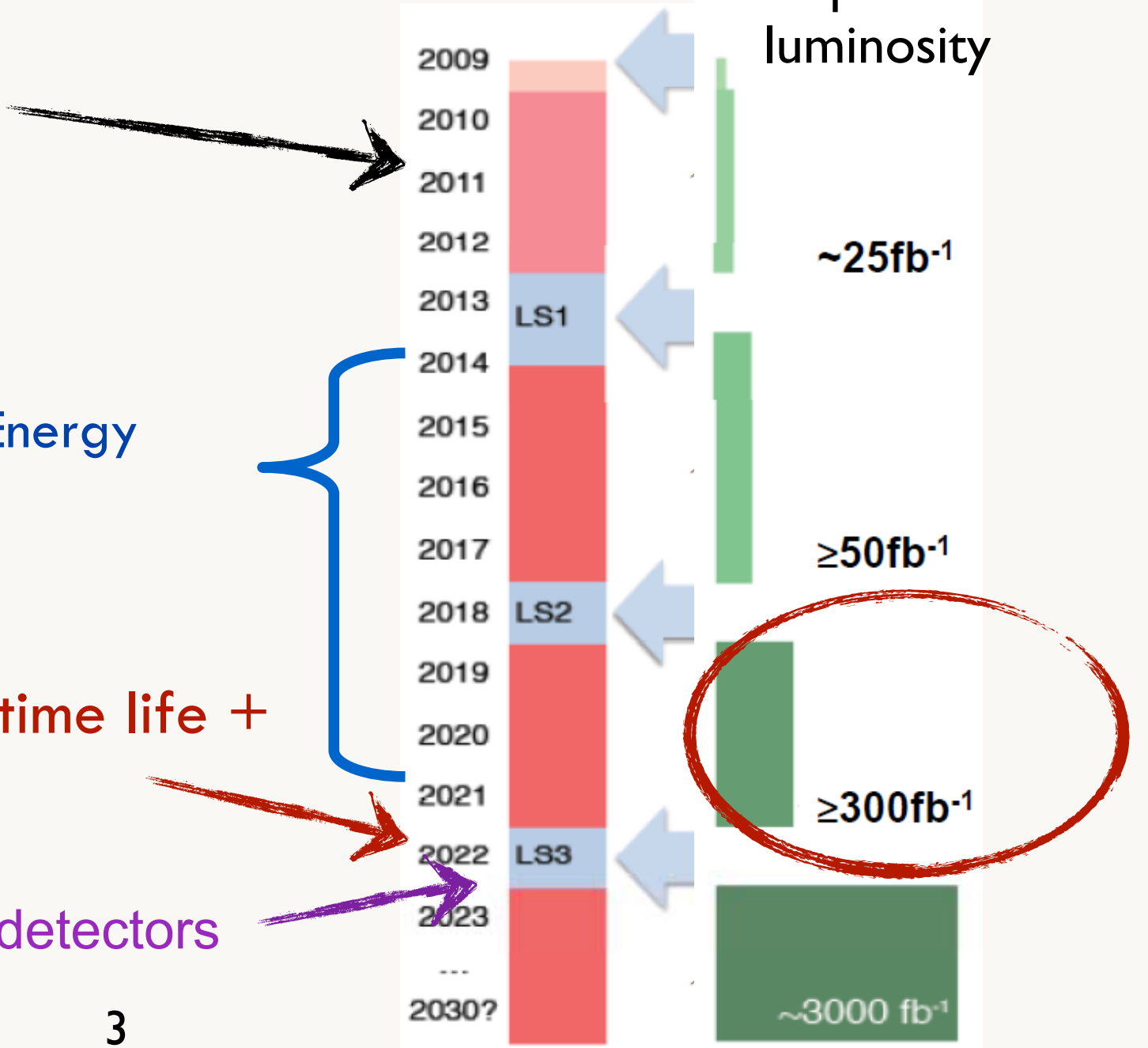

LHC upgrade: higher Luminosity and Energy $14 \mathrm{TeV} \& 1-2.10^{34} \mathrm{~cm}^{-2} \mathrm{~s}^{-1}$

More than $300 \mathrm{fb}^{-1}$ and $8-12$ years of time life + Luminosity effects

Complete new ATLAS tracker pixels and strip detectors 


\section{The IBL in the current ATLAS}

Upgrade the current Pixel detector with a new inner $4^{\circ}$ layer with finer segmentation
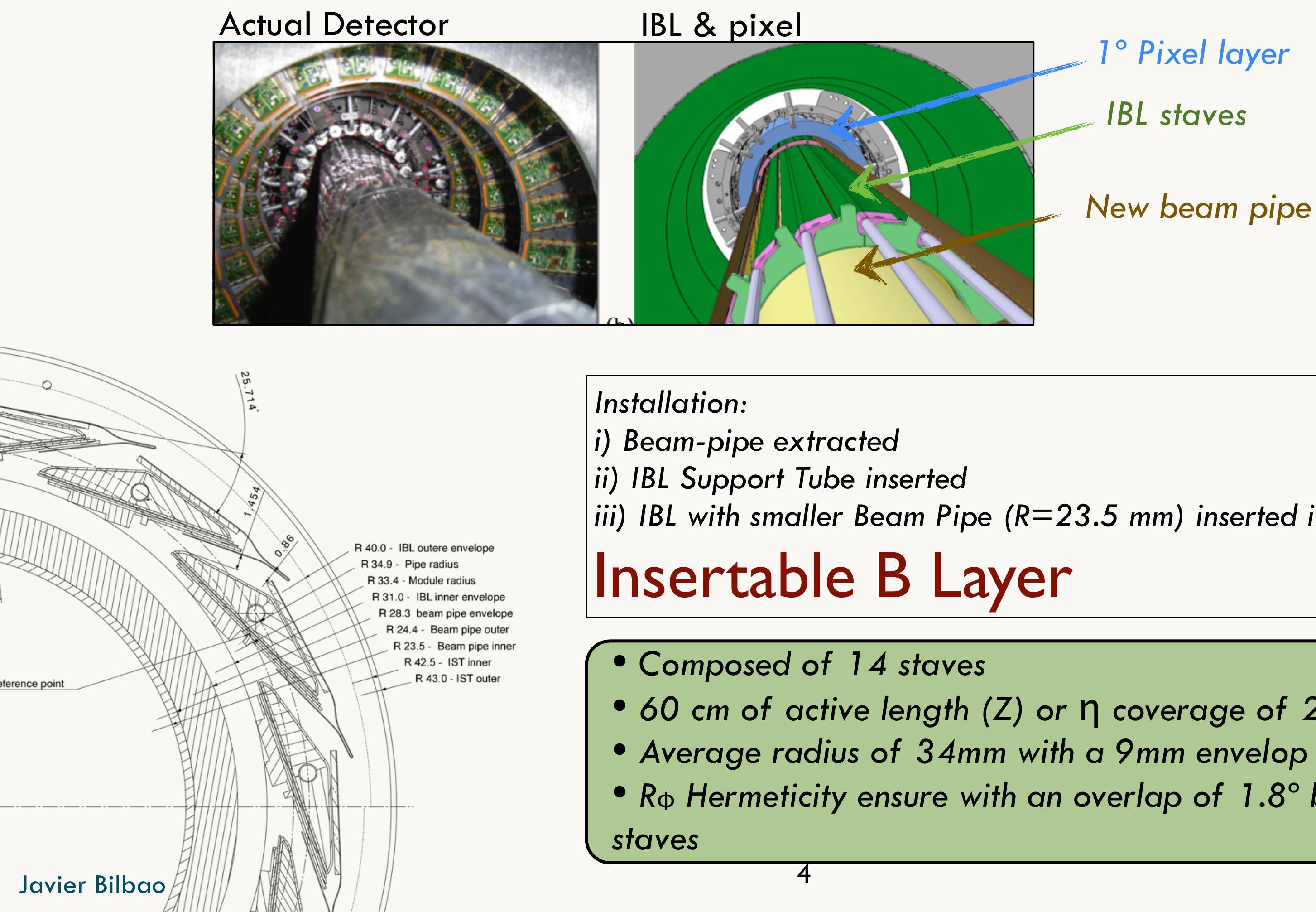

Installation:

i) Beam-pipe extracted

ii) IBL Support Tube inserted

iii) IBL with smaller Beam Pipe $(R=23.5 \mathrm{~mm})$ inserted in the IST

40.0- IBL outere envelop

R33.4- Module radius

R 31.0 - IBL inner envelope

R 24.4 - Beam pipe outer

23.5. Beam pipe inner

Insertable B Layer

R 42.5- IST inner

- Composed of 14 staves

- $60 \mathrm{~cm}$ of active length (Z) or $\eta$ coverage of 2.5

- Average radius of $34 \mathrm{~mm}$ with a $9 \mathrm{~mm}$ envelop

- $R_{\Phi}$ Hermeticity ensure with an overlap of $1.8^{\circ}$ between staves 


\section{IBL read out: new FE-I4}

FE-I3 inefficiency vs occupancy for B-layer

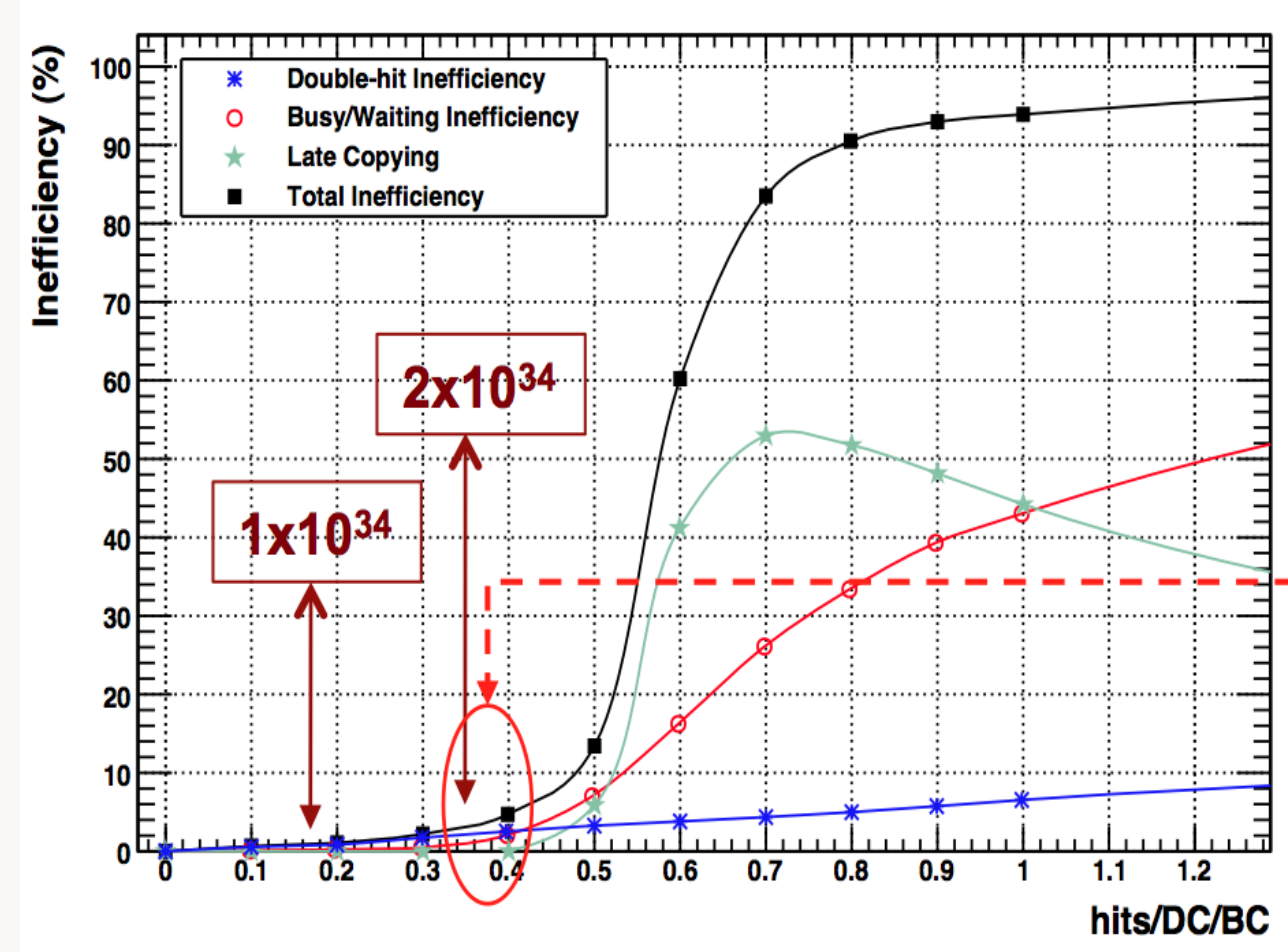

\section{FE-I4 vs FE-I3}

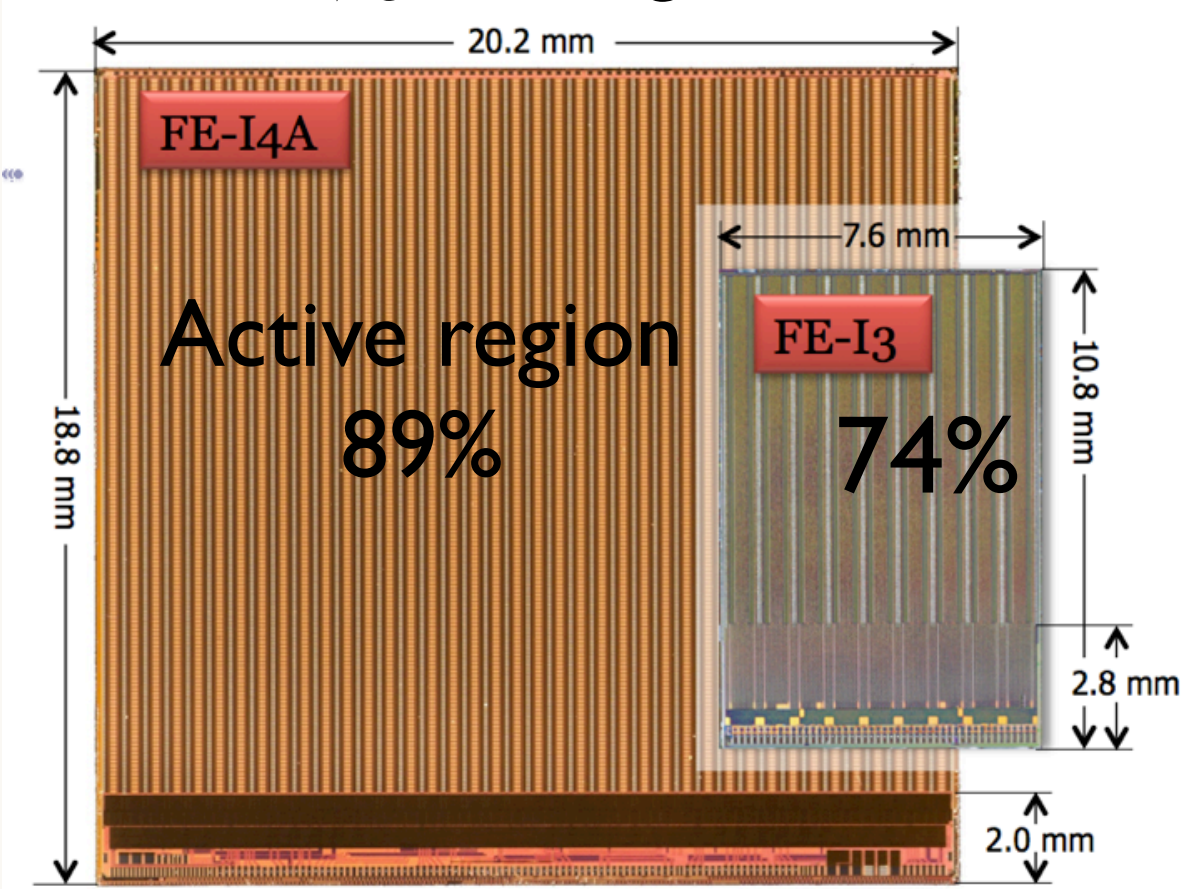

Javier Bilbao
Needs

Pixel size: $50 \times 250 \mu \mathrm{m}$

$336 \times 80$ (rows $\times$ cols)

Threshold: < $4000 \mathrm{e}^{-}$

Dispersion: $100 \mathrm{e}^{-}$

Noise: $<300 \mathrm{e}^{-}$

\section{Specifications}

$-150 \mathrm{~nm}$ thickness

- 130 um technology

- Charge resolution/TOT: 4 bits

- Analog preampfification

- Power consumption: $200 \mathrm{~mW} / \mathrm{cm}^{2}$

- Increase read out speed:

$160 \mathrm{Mb} / \mathrm{s}$

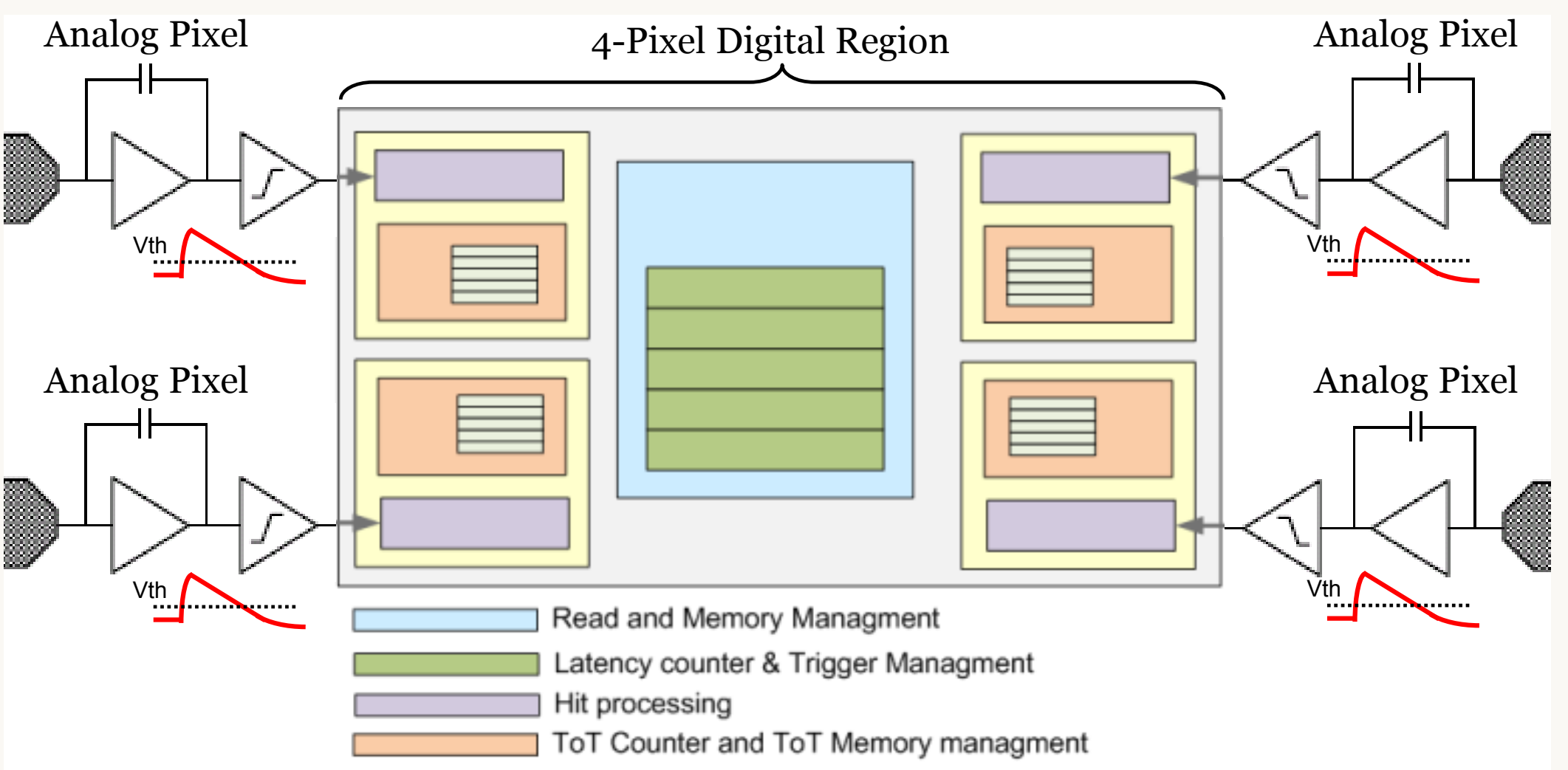




\section{D Sensor}

Front-end and sensor technology

Modules qualification after radiation

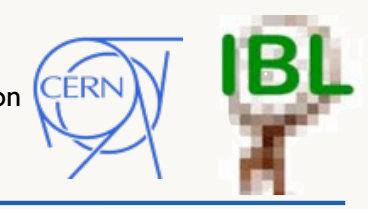

- 230um thick 3D $\mathrm{n}$ in p-type sensors

- Low operational bias Voltage: 20V (Close anode and cathodes)

- Slim edge 200 um, minimizing inactive region

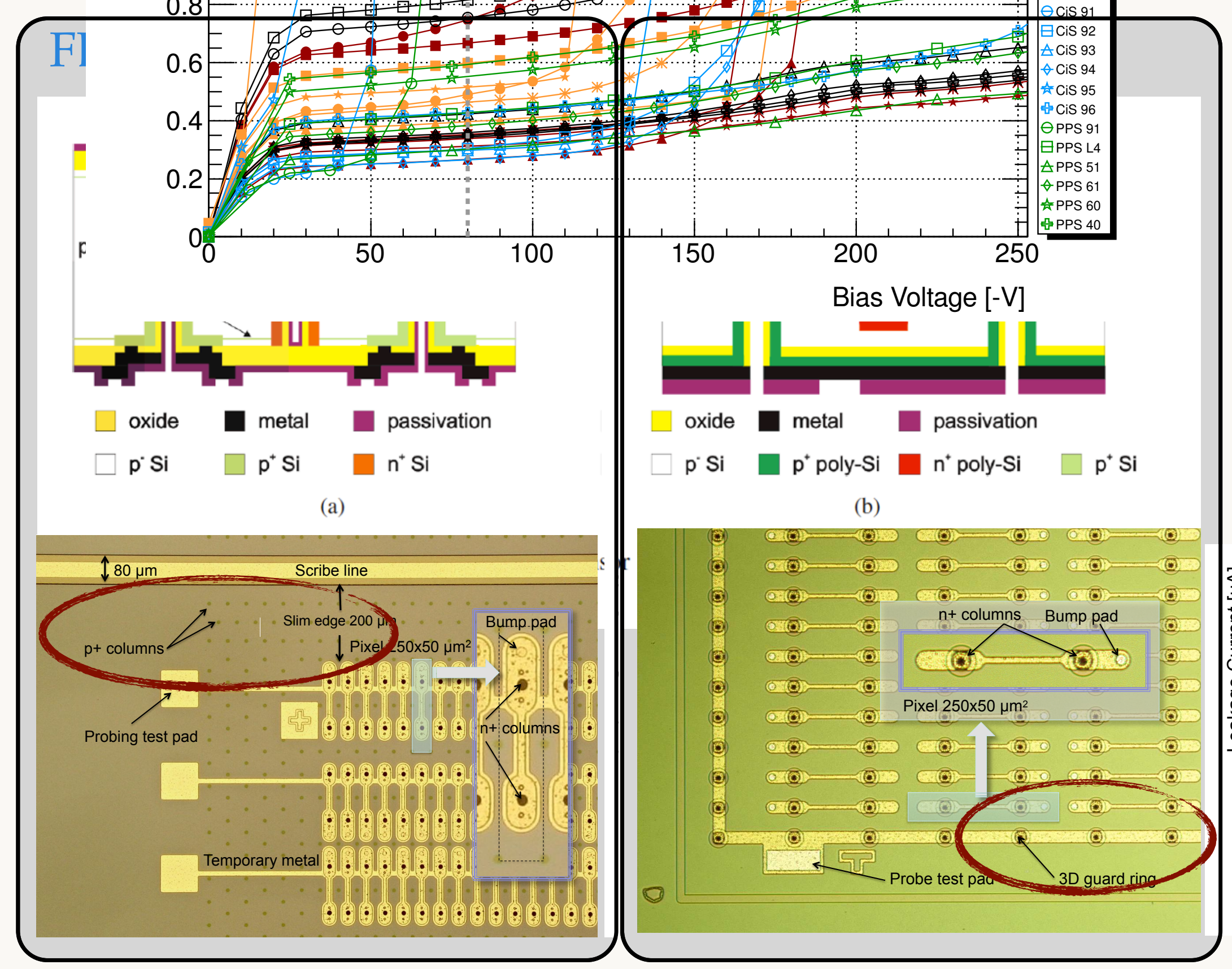

Operational module

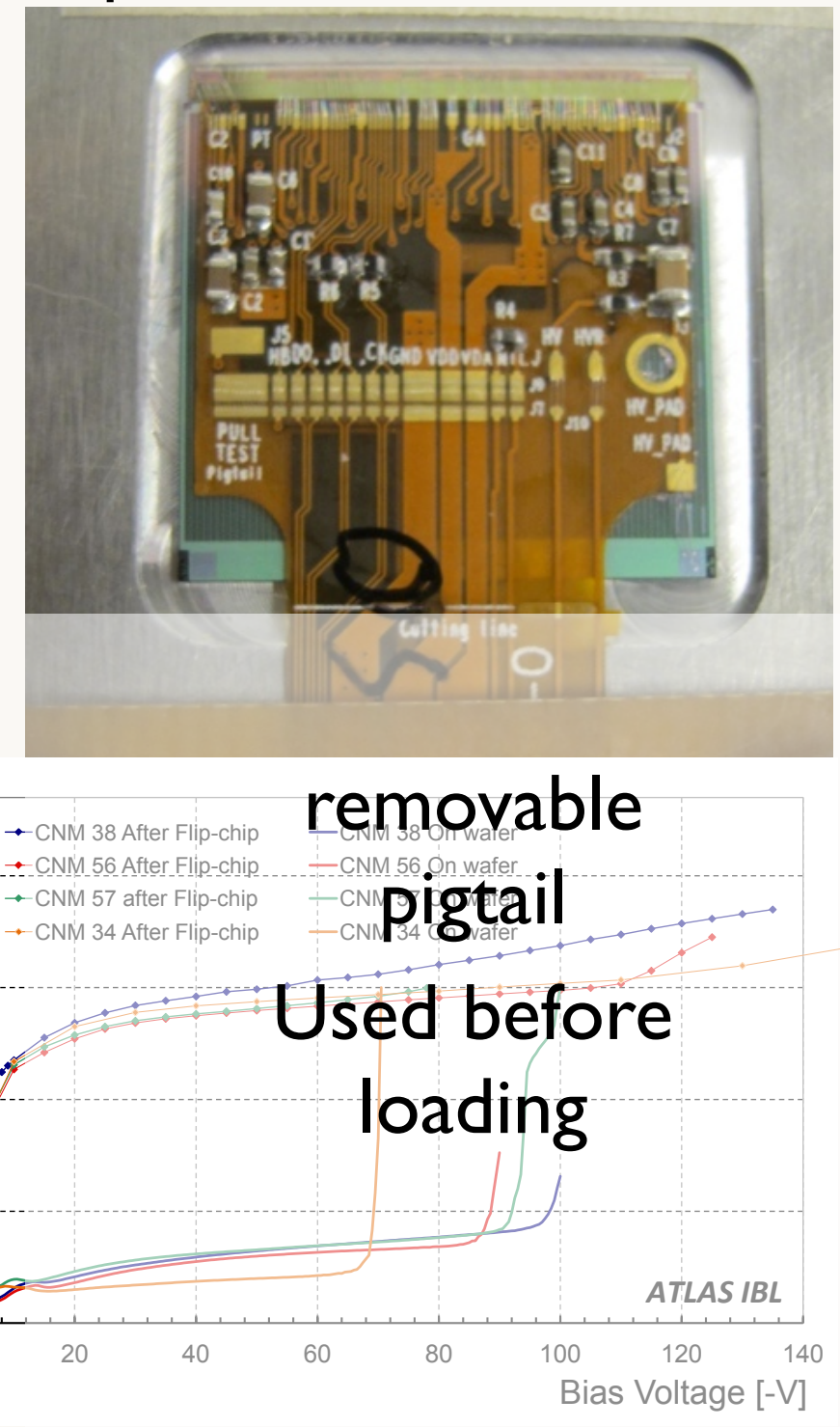




\section{Planar Sensor}

Front-end and sensor technology

- 200um thick $\mathrm{n}+$ in $\mathrm{n}$-type sensors

- Higher operational bias Voltage (-60V)

- Slim edge: Shifted guard rings (13) underneath active pixels

- Border pixels larger : 500 um (border efficiency)

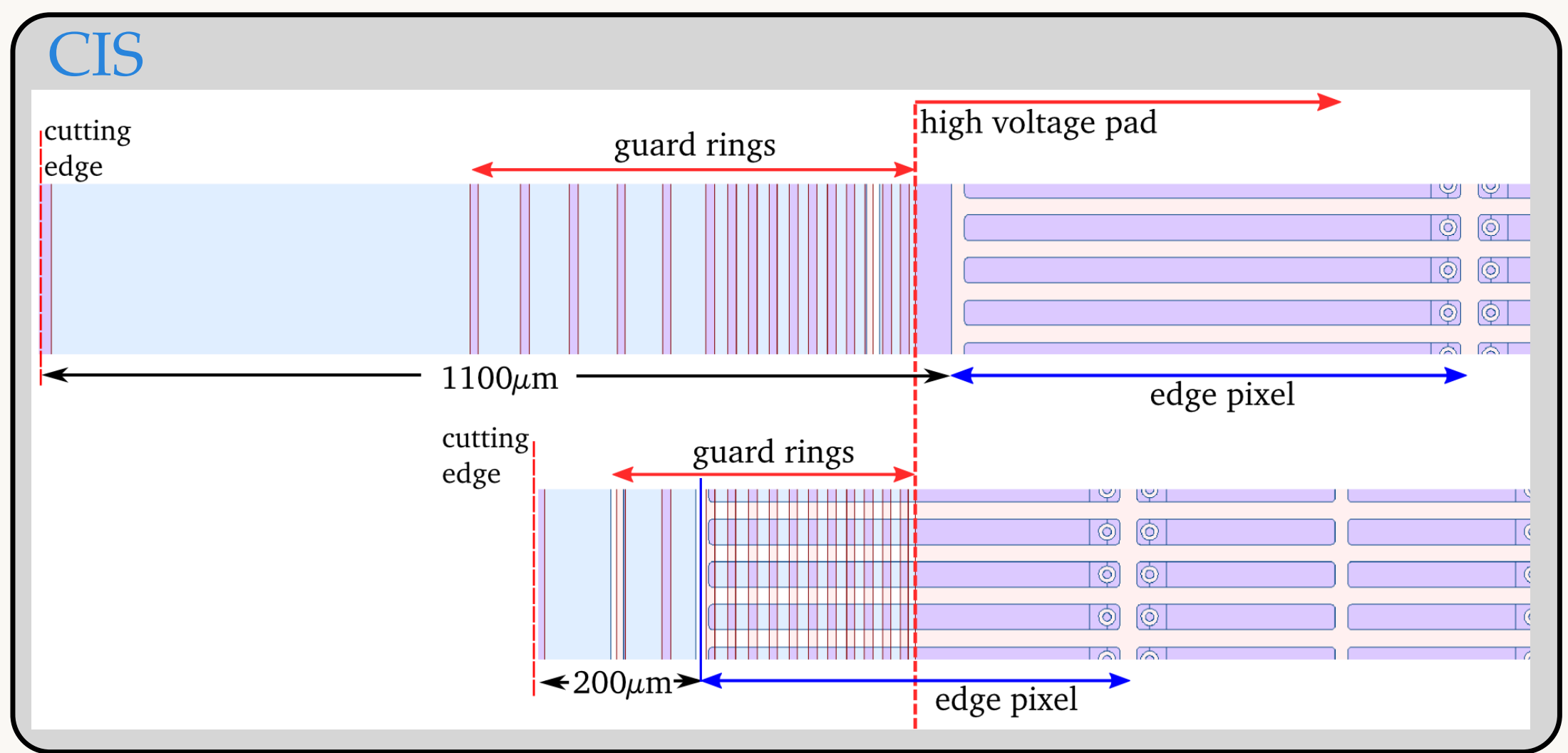

Outer area has been proven to remain active for 200 um thick detector $\mathrm{Vb}=-60$. Improved after type inversion 


\section{IBL Module qualification}

Total expected Luminosity (IBL life): $500 \mathrm{fb}^{-1}$

$\rightarrow 250 \mathrm{Mrad}$ TID and $5.10^{15} \mathrm{n}_{\text {eq }} / \mathrm{cm}^{2}$ NIEL

\section{IBL specification after radiation:}

Power dissipation of $200 \mathrm{~mW} / \mathrm{cm}^{2}$ at $-15 \mathrm{C}$ tracking efficiency $>97 \%$.

Irradiation with $25 \mathrm{MeV}$ proton beam up to $750 \mathrm{MRad}$ (KIT) and reactor neutron up to $250 \mathrm{MRad}(\mathrm{TRIGA})$

\section{IV after irradiation:}

\section{FBK}

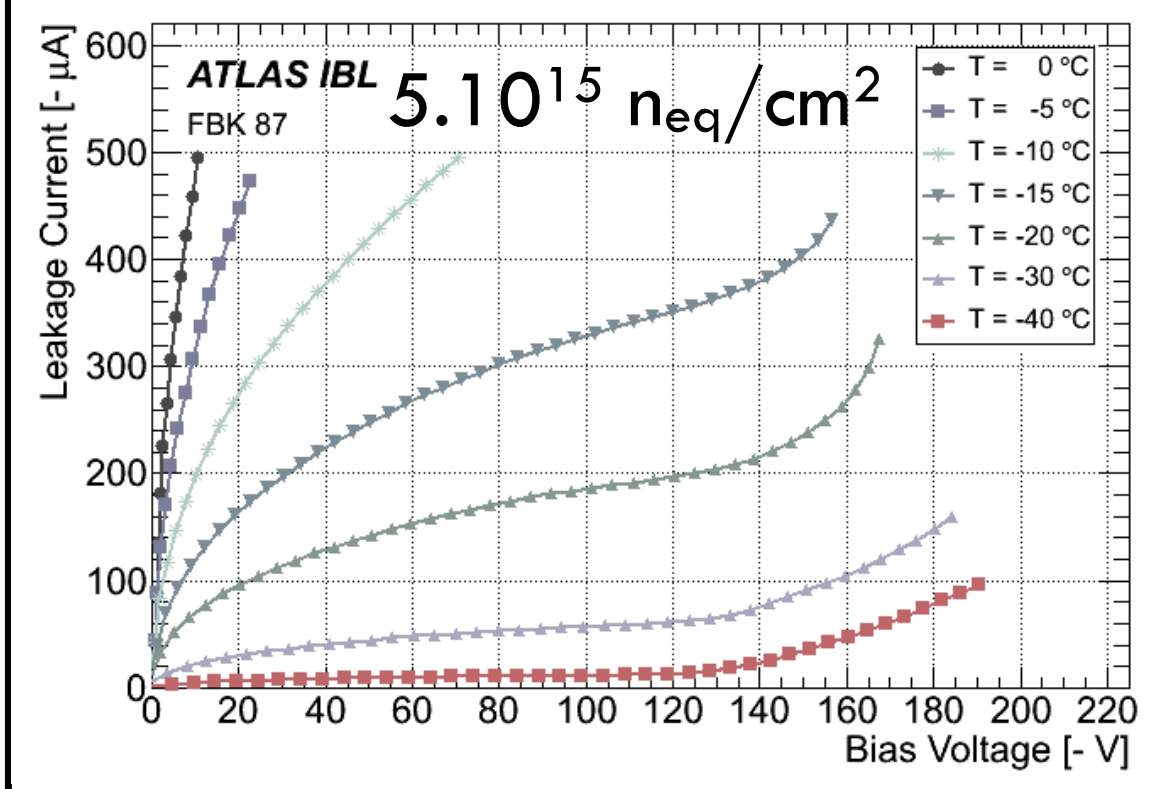

Javier Bilbao

\section{$\mathrm{CNM}$}

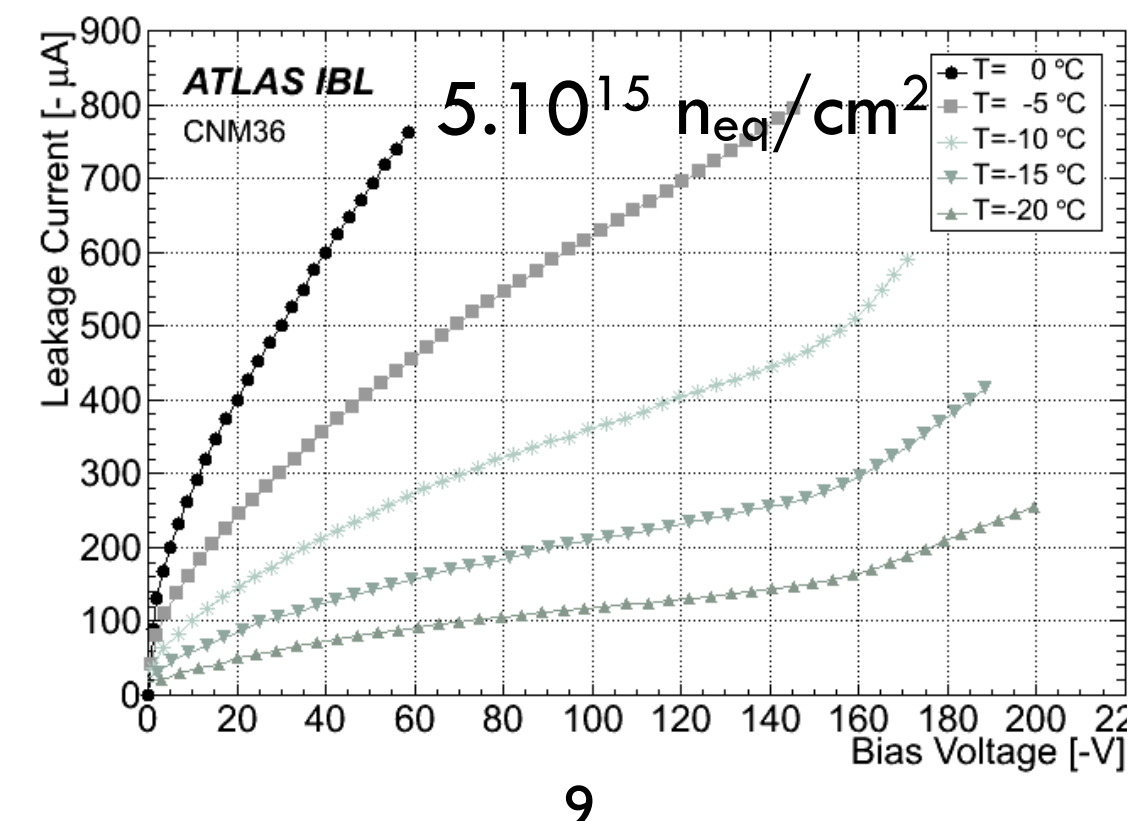

9

\section{CIS}

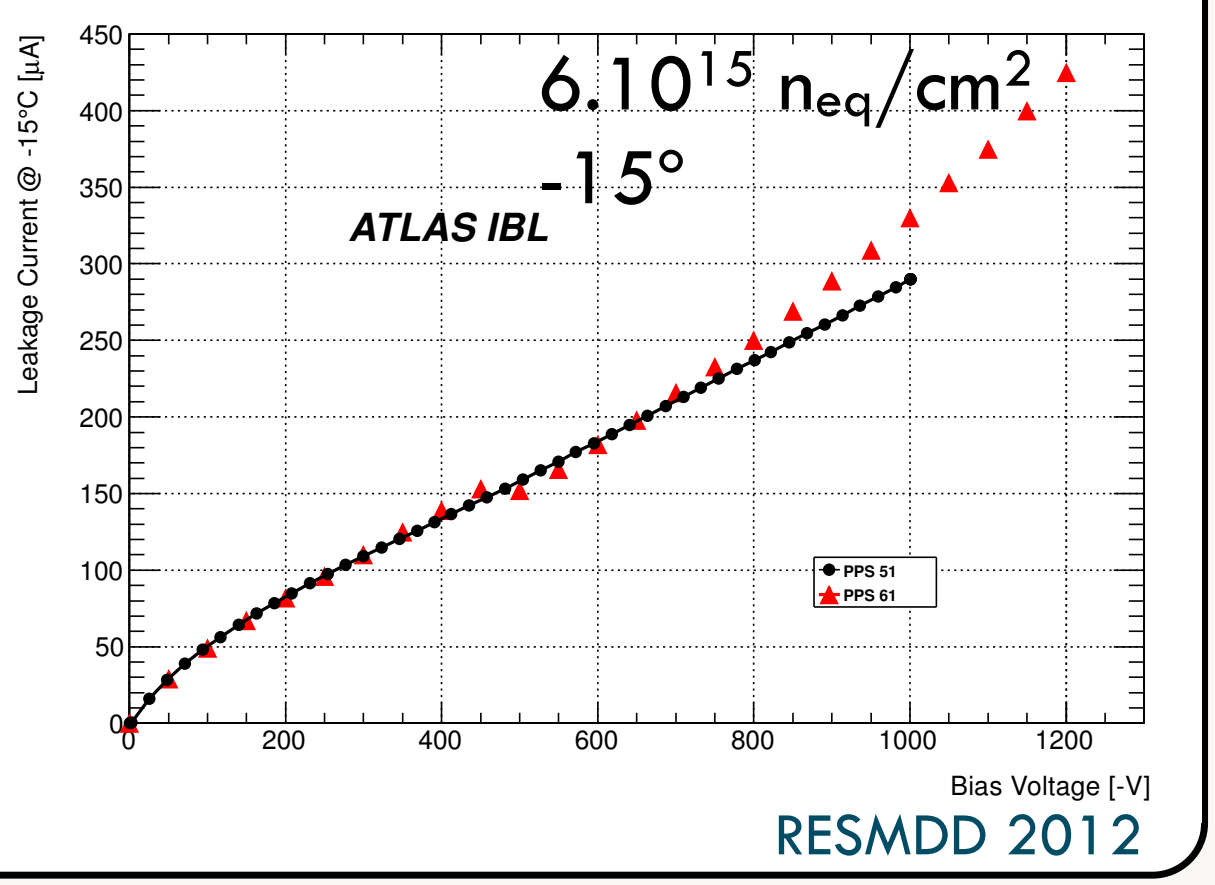




\section{D after radiation}

Front-end and sensor technology

\section{Charge collection}

ToT distribution Aft Ir.

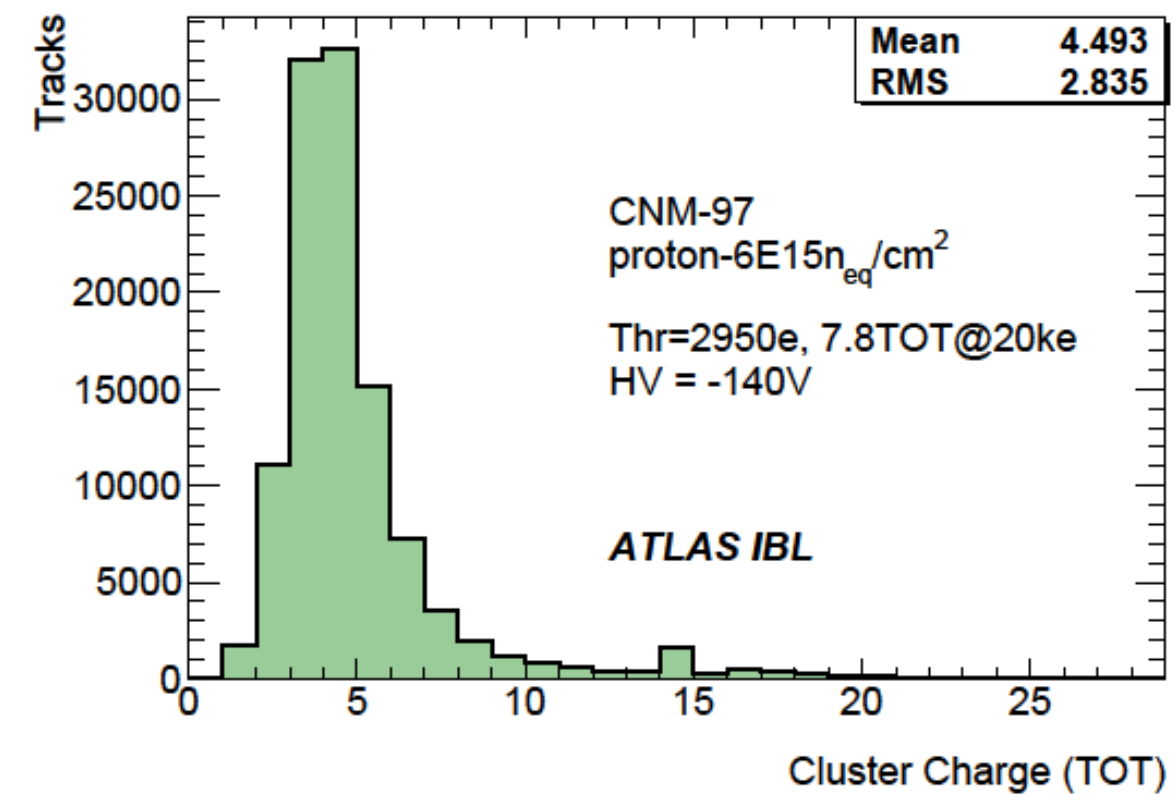

ToT Bf \& Aft Ir.

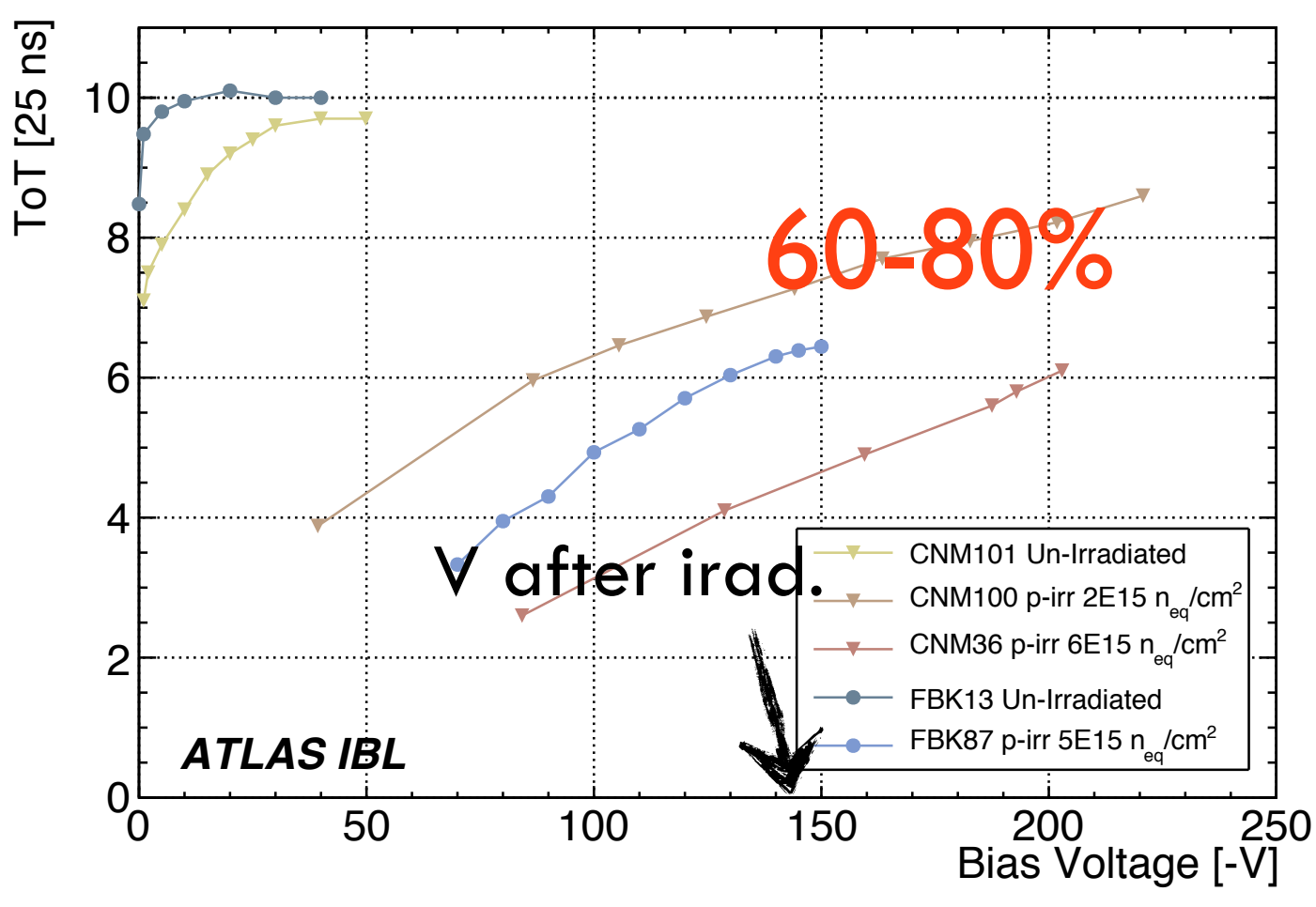

Noise Bf \& Aft Ir.

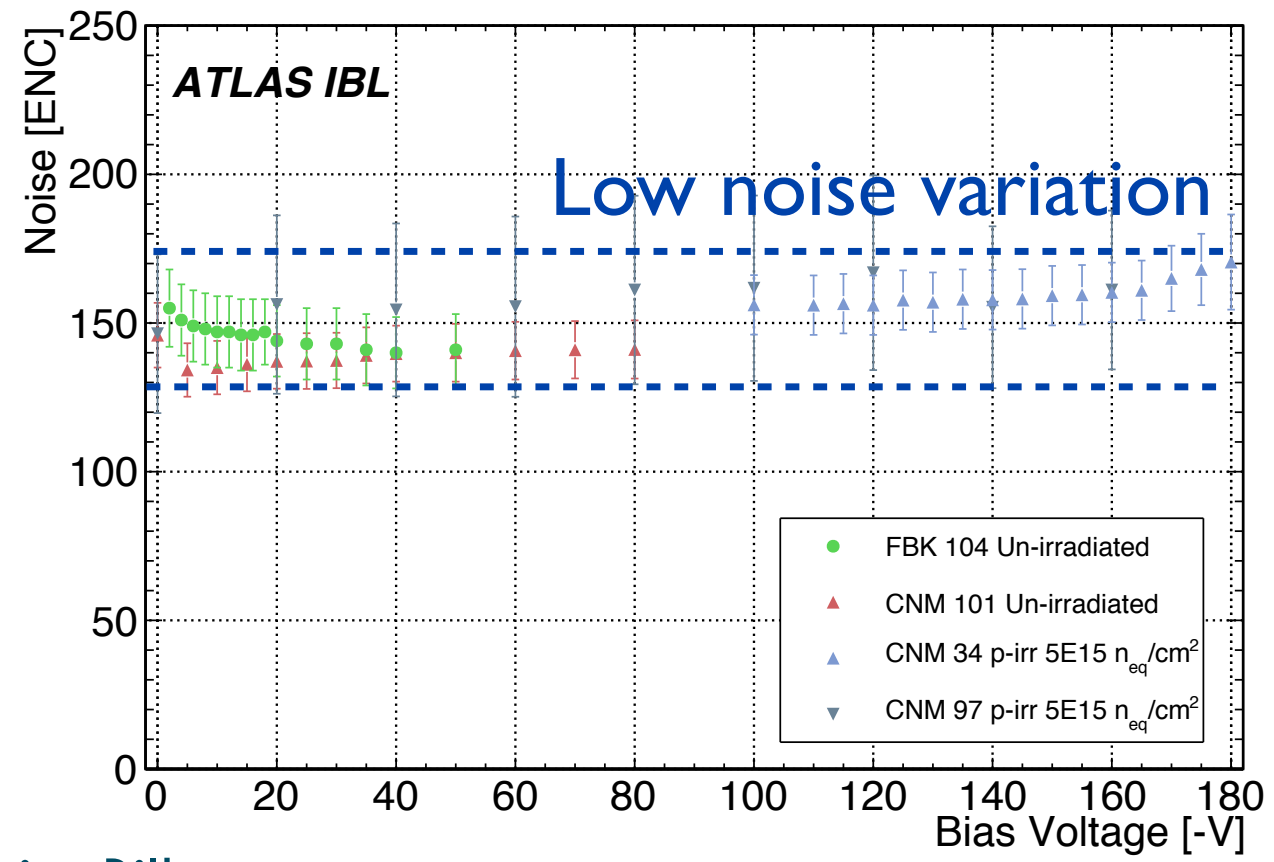

Javier Bilbao
Active Area \& Resolution Aft Ir.
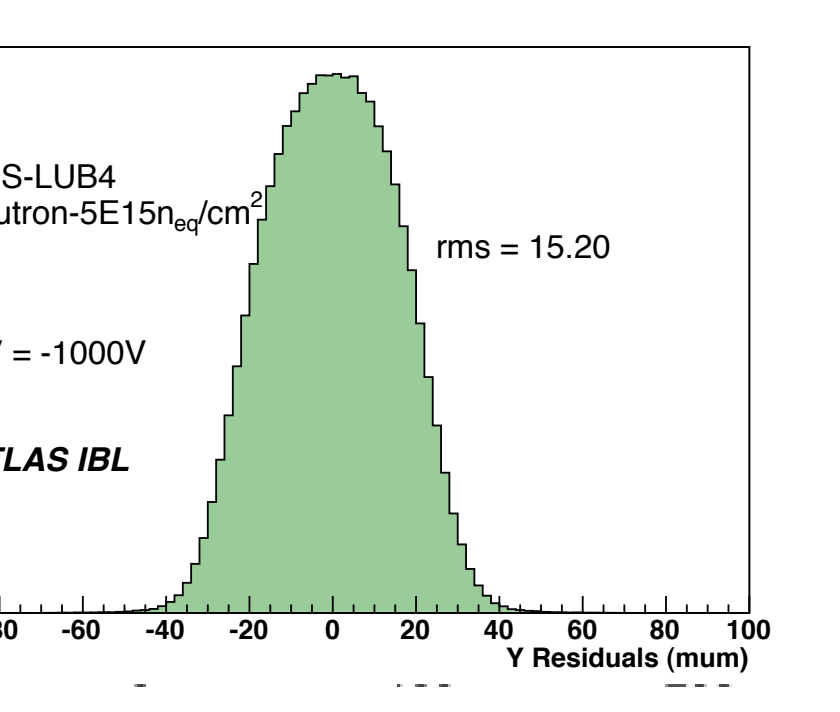

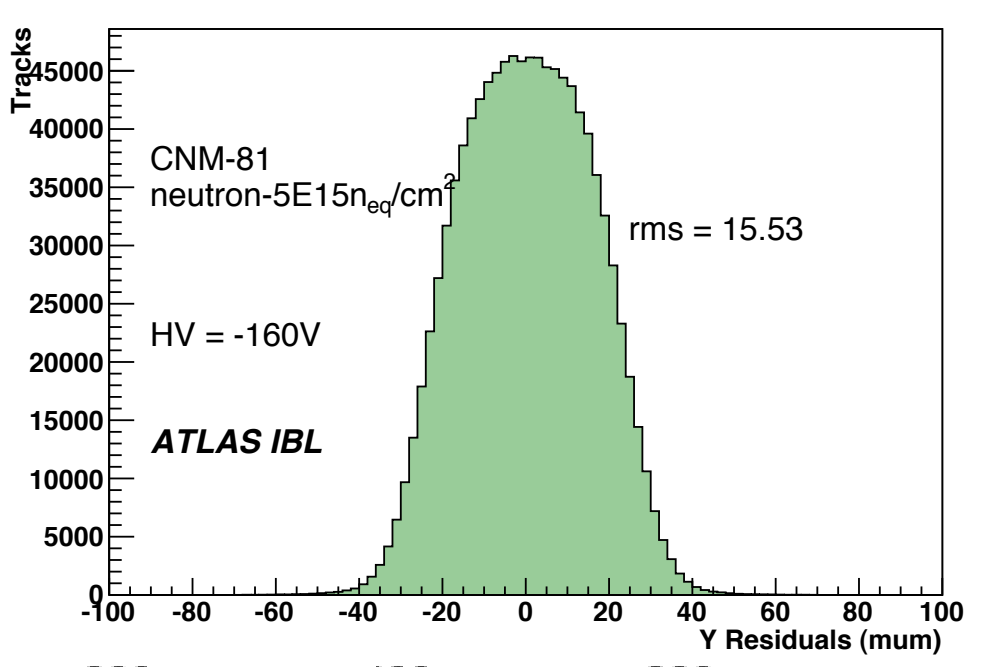

(b) 


\section{Charge collection}

ToT Bf \& Aft Ir.

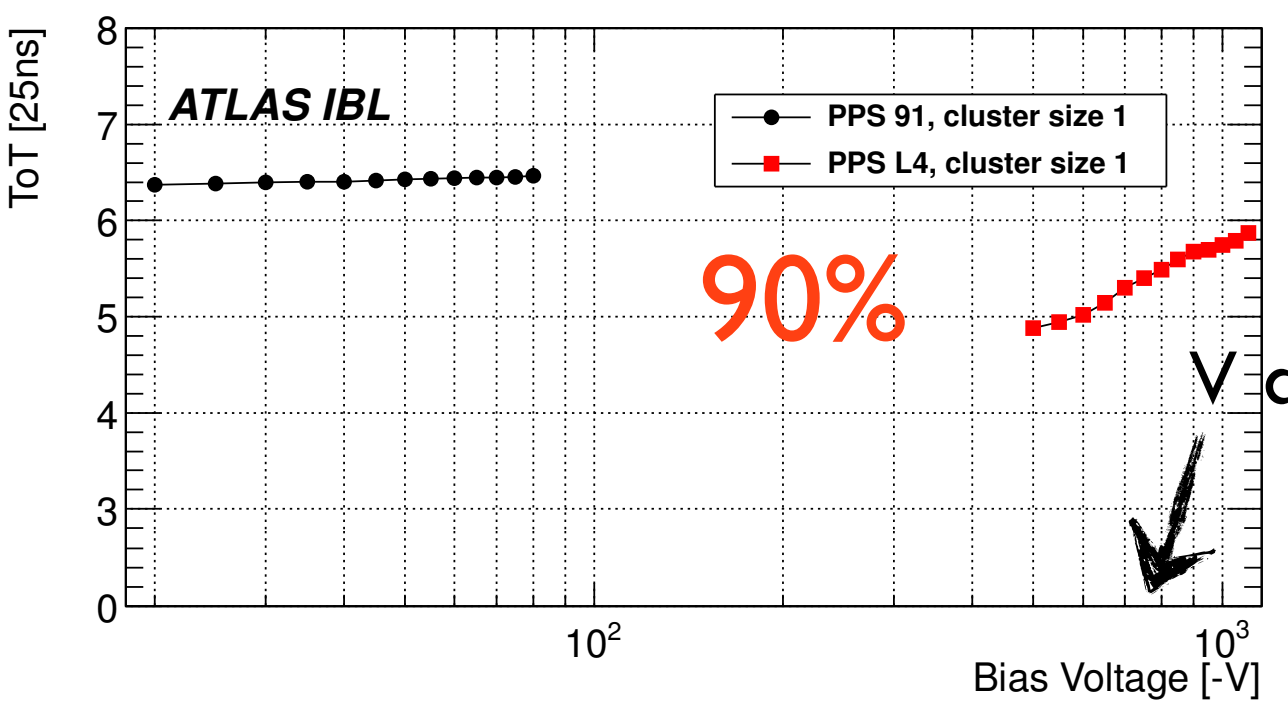

ToT distribution Aft Ir.

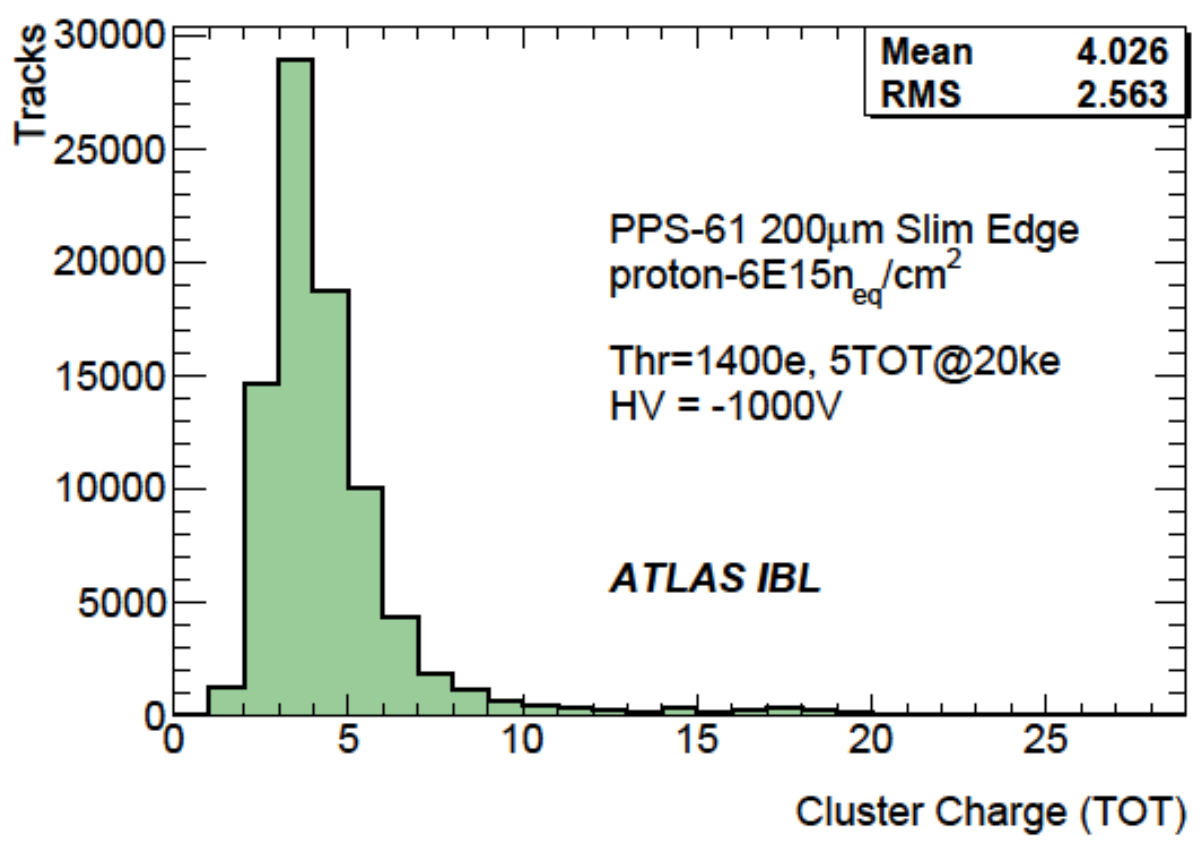

Noise Bf \& Aft Ir.

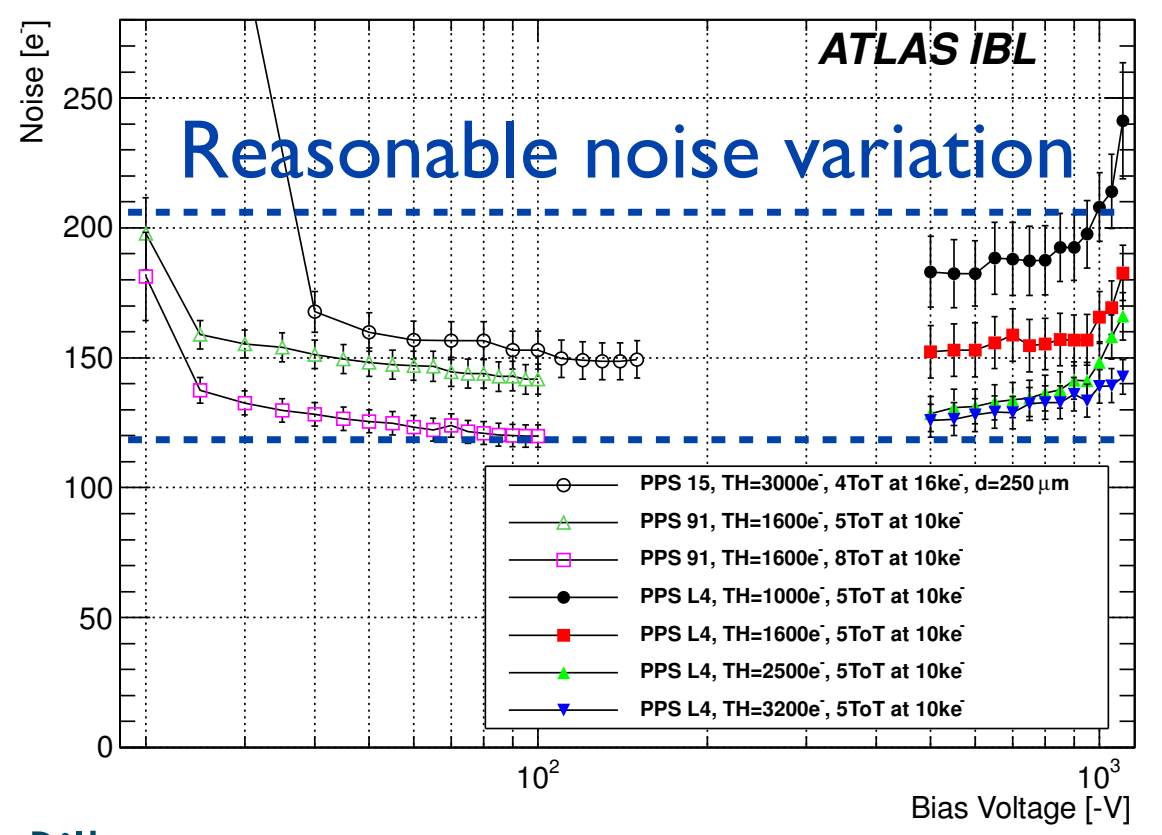

Javier Bilbao
Active Area \& Resolution Aft Ir.
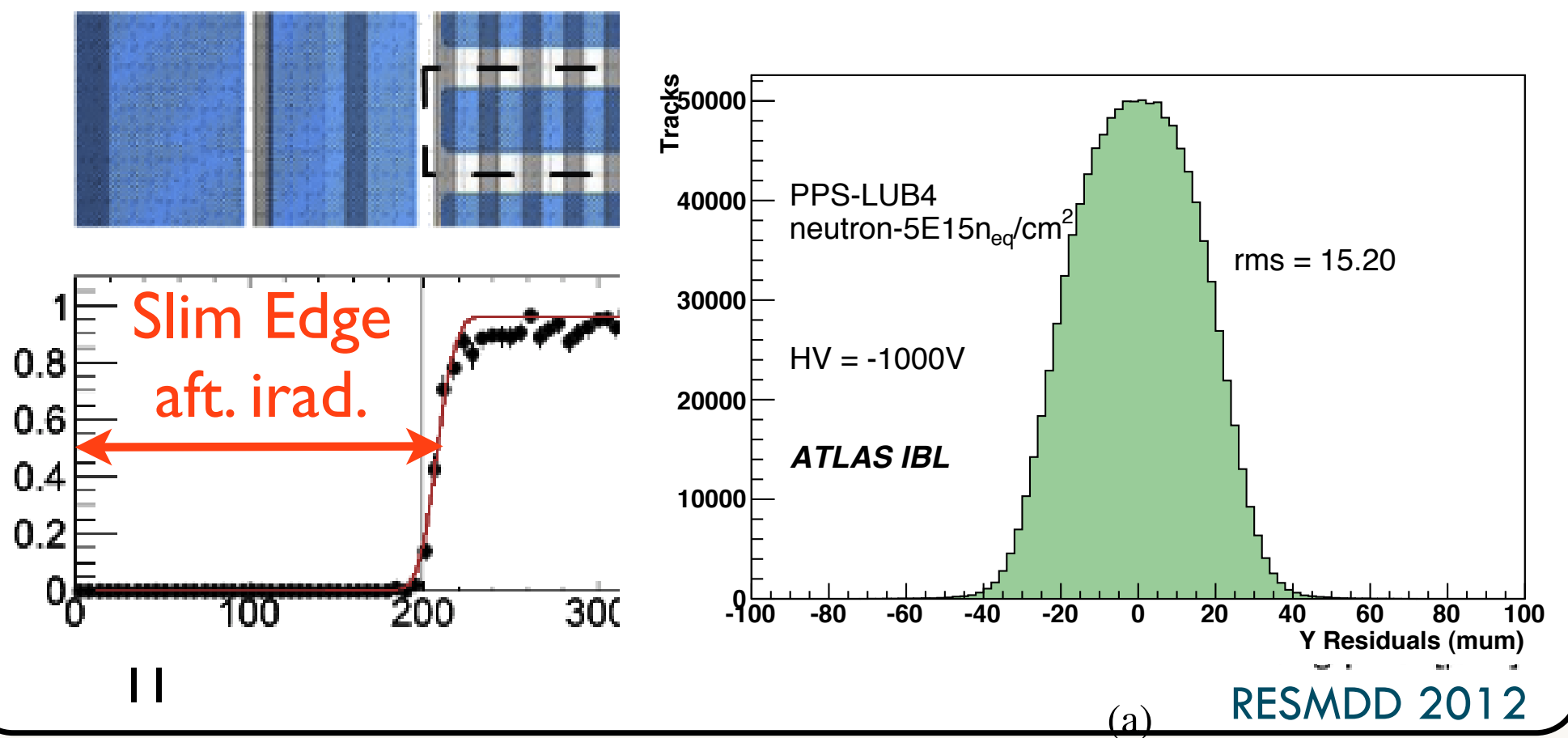


\section{Stave-0 Loading}
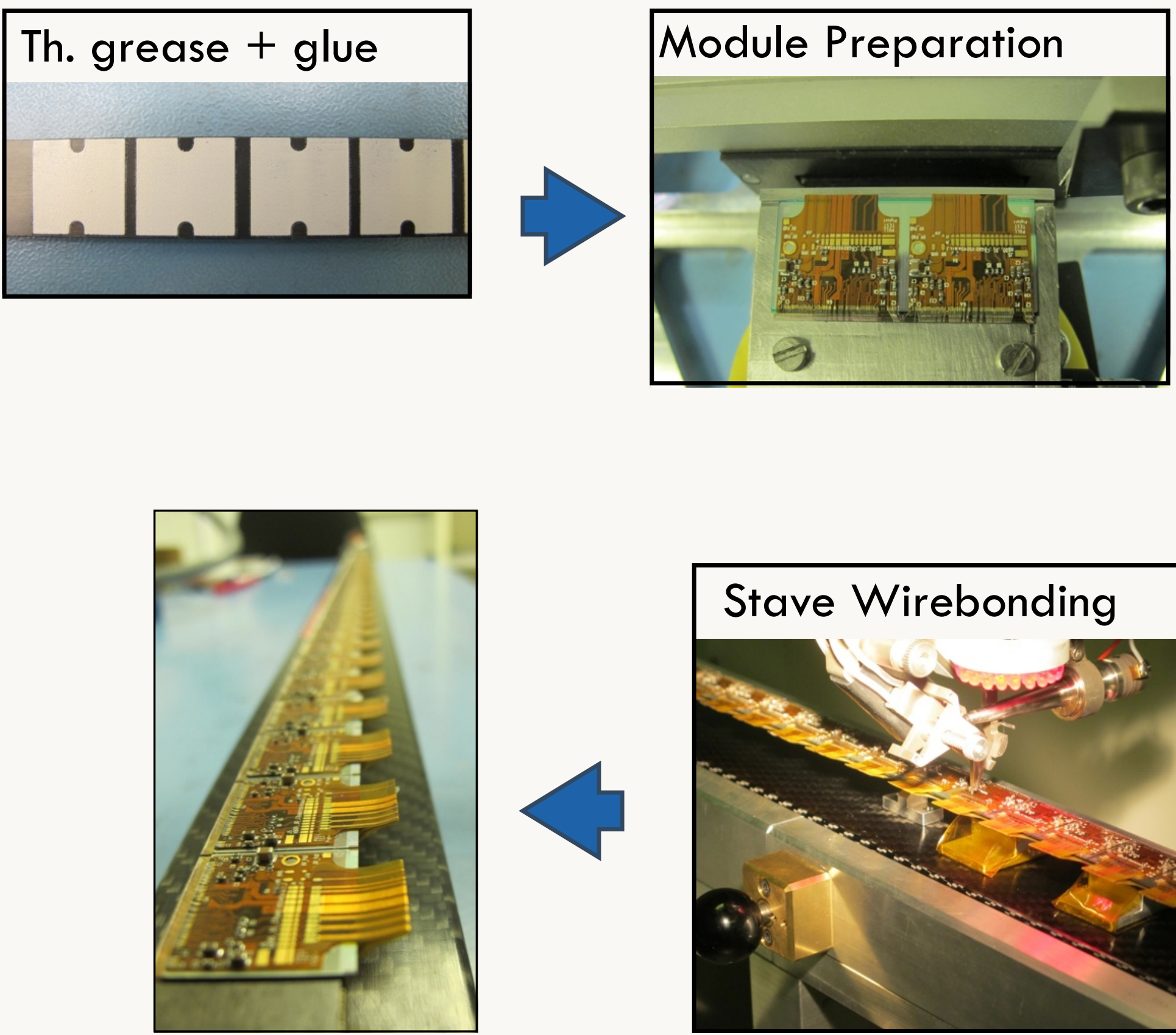
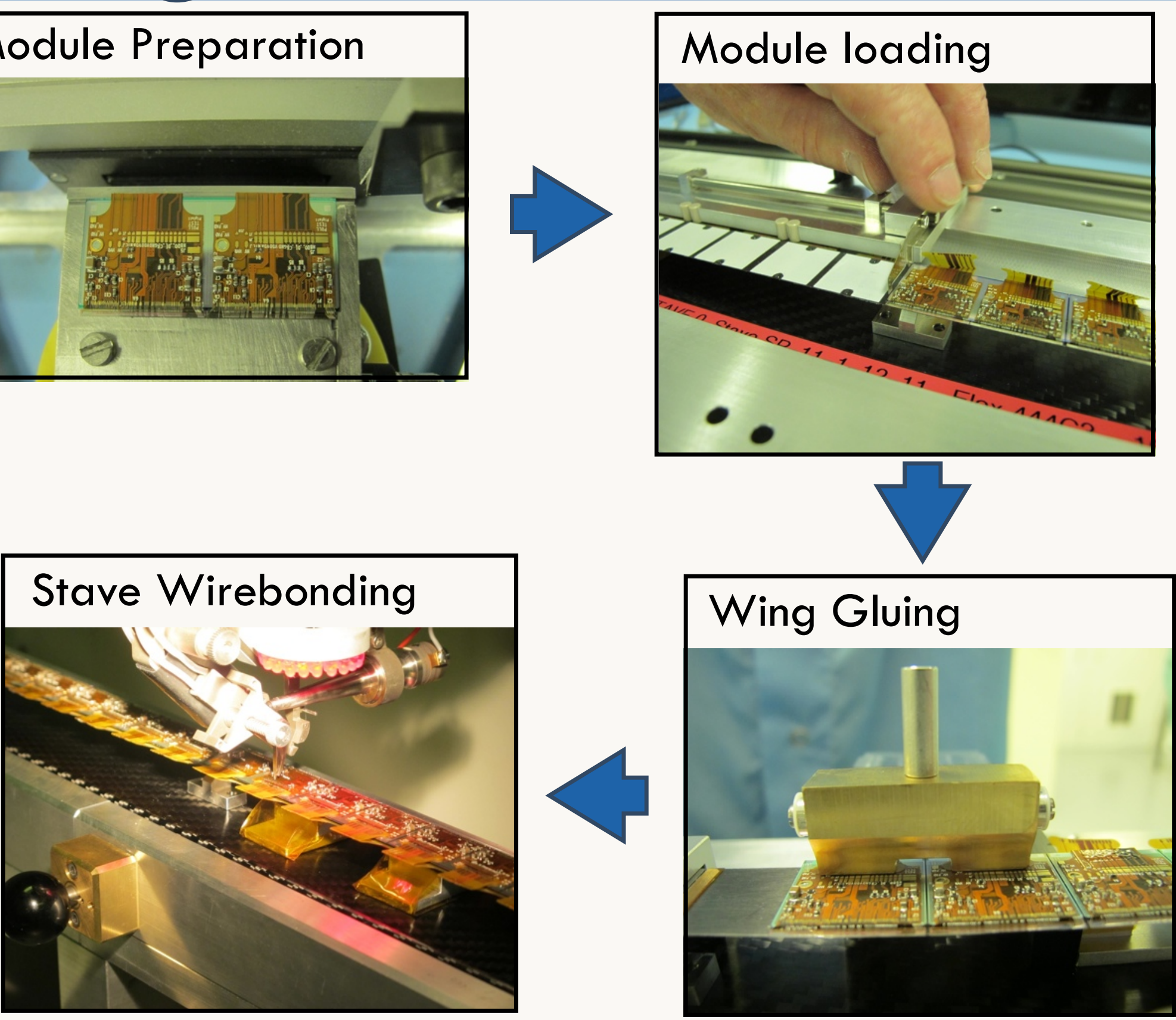

Stave QA: - Optical inspection

- Electrical test (LV, HV) \& NTC read-out

- Sensor crosscheck (IV)

- Individual module and global stave response (Analog, Digital, Threshold, ...) 


\section{Threshold Scan}

- Modules can run in single module tests at 1500 e- threshold

- Full stave can be tuned with a threshold of $3000 \mathrm{e}^{-}$and 6TOT @20 -> The goal is to tune the stave up to th. lower than $2000 \mathrm{e}^{-}$

- Noisy pixel : 0.02\%(A-side) and 0.1\% (C-side) [A-side loaded with Green modules, $\mathrm{C}$-side loaded with green and orange modules]

A-side Threshold Mean Value

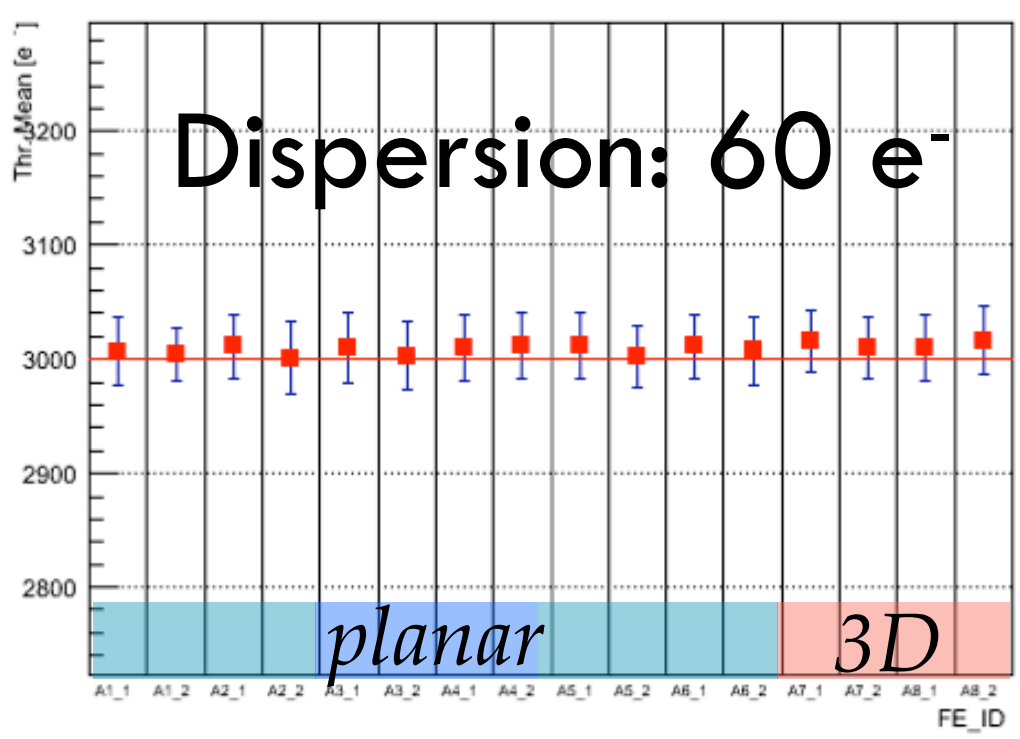

C-side

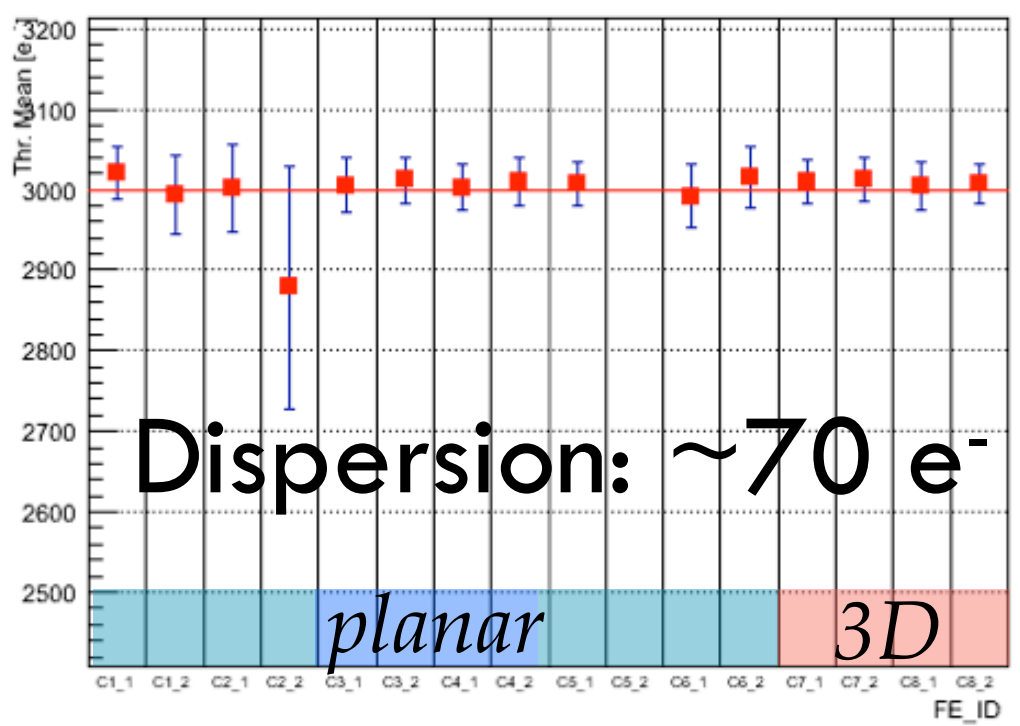

Sigma Mean Value

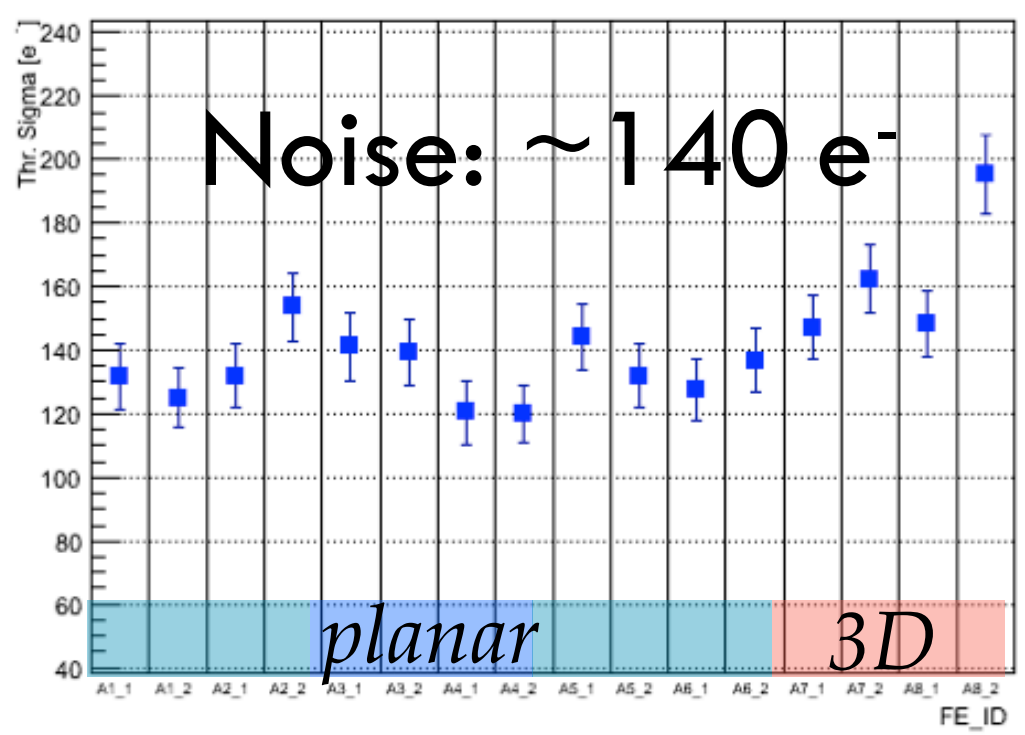

-.....-

Sigma Mean Value

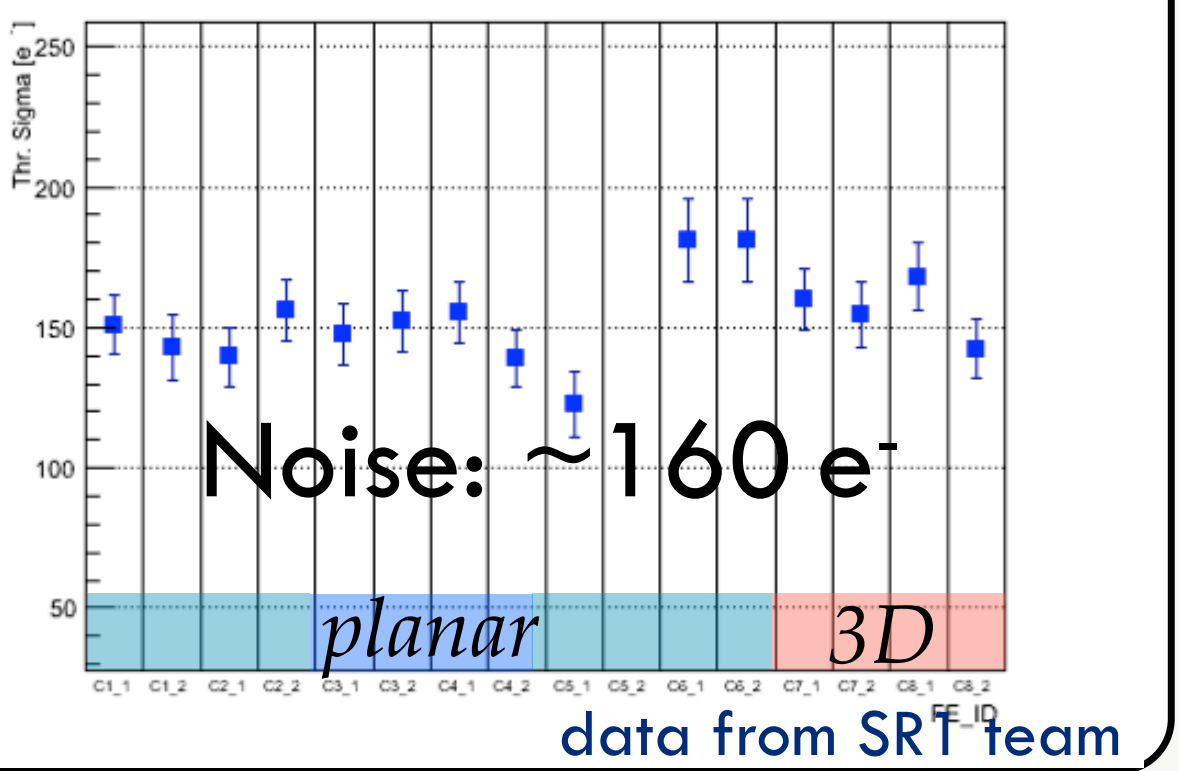




\section{Source Scan}

Front-end and sensor technology

Performed with 2 sources of $\mathrm{Am}^{241}$

Source scan for different source position

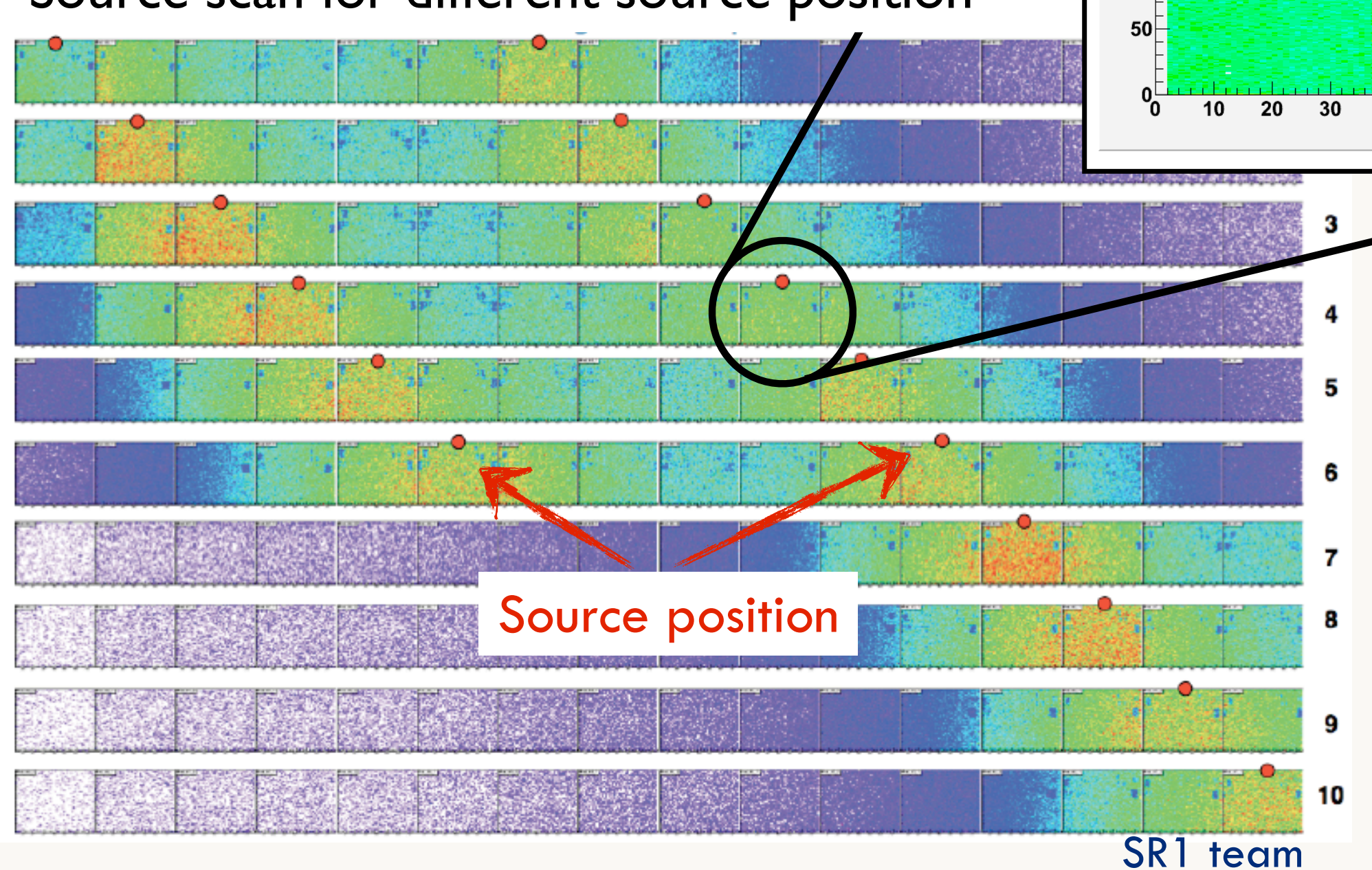

\section{TOT distribution:}

ToT Mod 66030225 at A3-1

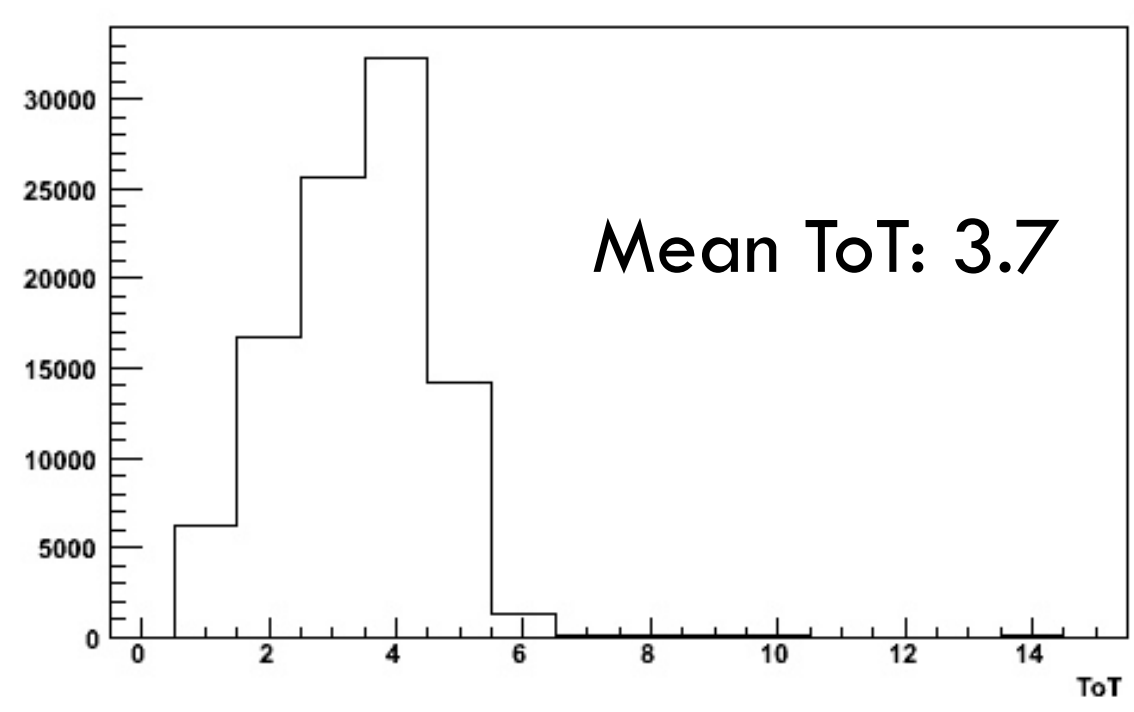




\section{Schedule}

\begin{tabular}{|c|c|c|c|}
\hline Activities & Starting & Ending & \multirow{7}{*}{$\begin{array}{l}\sim 6 \text { weeks delay } \\
\text { Modification after } \\
\text { reviews } \\
\sim 2 \text { month shifted }\end{array}$} \\
\hline FEI4-B & Sept 11: Submission & $\begin{array}{l}\text { Dec } 11 \text { received first chips, Aug } 12 \\
\text { received all remaining wafers, testing } \\
\text { ongoing }\end{array}$ & \\
\hline Bump bonding & Aug 11: pre-production & Nov 12: Completion (incl. Spares) & \\
\hline Module assembly & $\begin{array}{l}\text { End May 12: } 1^{\text {st }} \text { modules ready } \\
\text { for loading }\end{array}$ & Feb 13 (spare and contingency incl) & \\
\hline Module loading & $\begin{array}{l}\text { Aug } 12: \rightarrow 4 \text { staves to be ready } \\
\text { by Oct } 12\end{array}$ & $\begin{array}{l}\text { May 13: Completion (spare and } \\
\text { contingency incl) }\end{array}$ & \\
\hline Stave loading & $\begin{array}{l}\text { Mar 13: starting with the } 1^{\text {st }} \text { large } \\
\text { batch of available staves }\end{array}$ & Sept 13: Completion & \\
\hline $\begin{array}{l}\text { Final tests and } \\
\text { commissioning }\end{array}$ & Nov 13 & $\begin{array}{l}\text { April 14: IBL Installation } \\
\text { (Nov } 13 \text { with contingency) }\end{array}$ & \\
\hline
\end{tabular}

from: H. Pernegger

Actual goal is to produce:

Stave 0-B during October

Start production in November having 4 staves before Christmas

\section{LHC Shut-down postponed of 3 months}




\section{Conclusion}

- Very demanding program:

- New FE with pixel size of $50 \times 250 \mu \mathrm{m}$ fully characterized

- 2 large scale pixel sensor technologies used (3D-planar)

- Engineering challenge saving material budget and the light stave approach

- All components were irradiated up to final IBL fluences showing no critical damages and maintaining performance

- First full assembly stave with great and very promising performance

- Starting production on the following weeks (producing up to 2 times the required staves needed) 


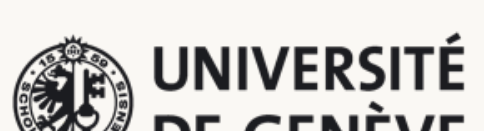

DE GENĖVE

Back up slides...

17 


\section{LHC program \& Implication
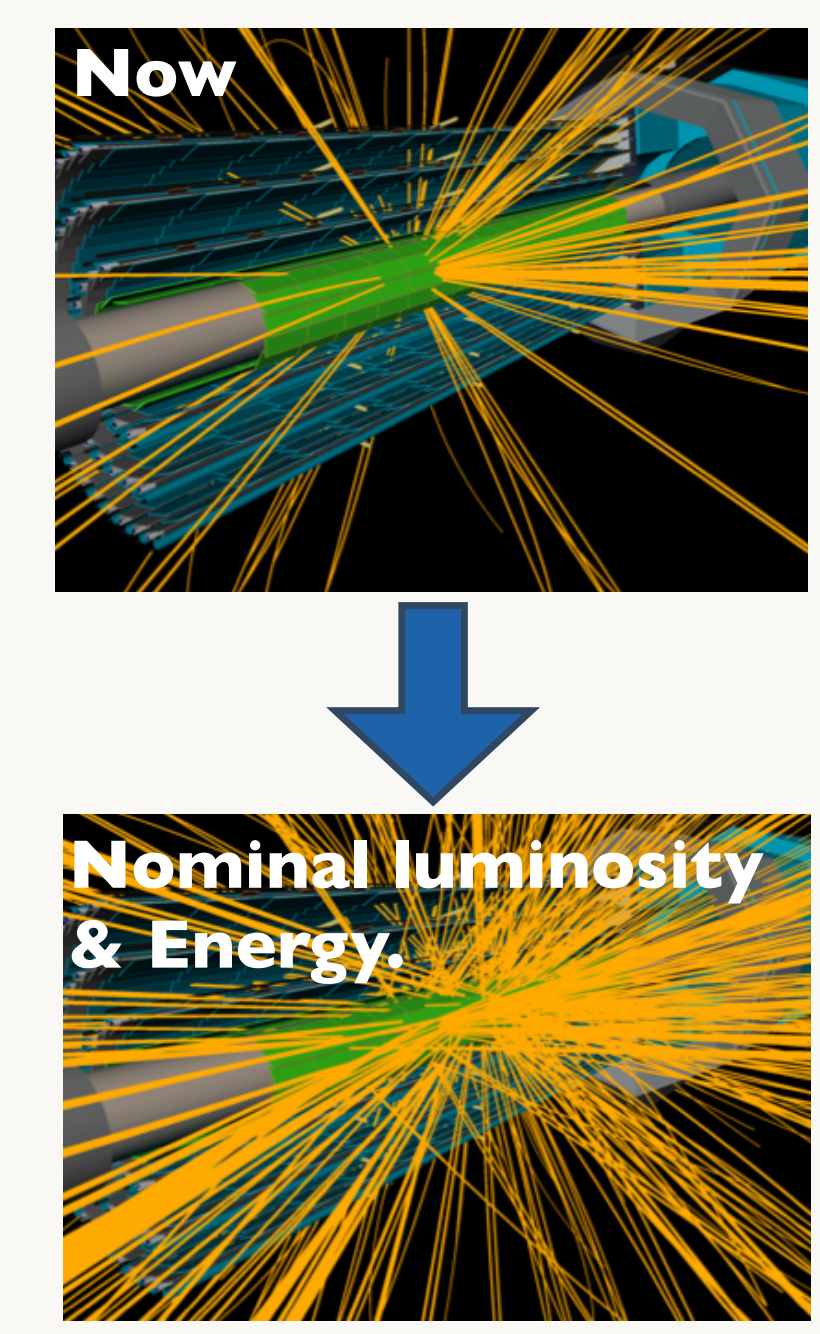

FE-I3 inefficiency vs occupancy for B-layer
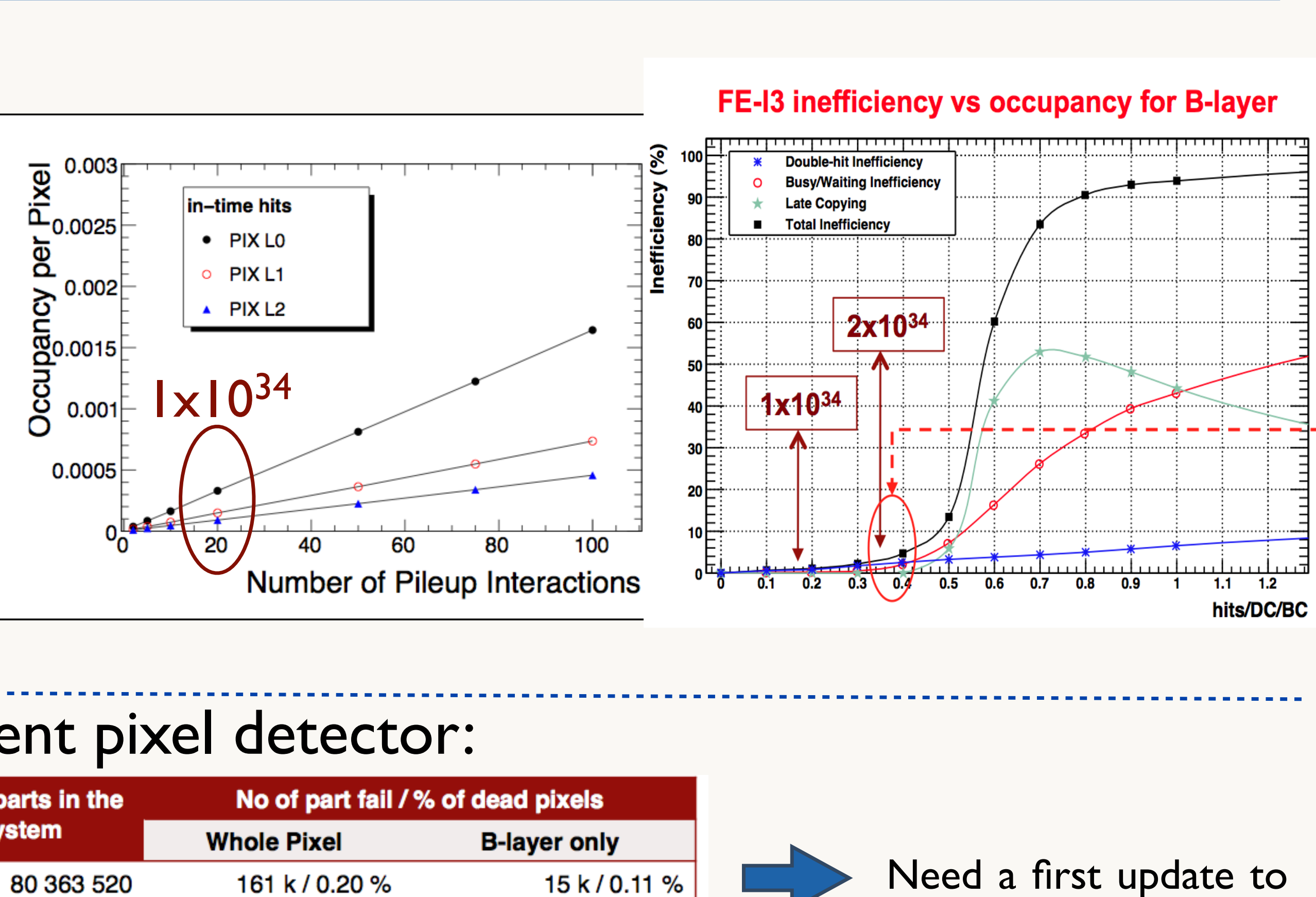

\section{Status of the current pixel detector:}

\begin{tabular}{|lrrr|}
\multicolumn{1}{c}{$\begin{array}{c}\text { Affected System } \\
\text { (failure classes) }\end{array}$} & $\begin{array}{c}\text { No. of parts in the } \\
\text { system }\end{array}$ & \multicolumn{2}{c|}{ No of part fail / \% of dead pixels } \\
\hline Pixel & 80363520 & $161 \mathrm{k} / 0.20 \%$ & $15 \mathrm{k} / 0.11 \%$ \\
\hline Front-end & 27904 & $42 / 0.15 \%$ & $9 / 0.20 \%$ \\
\hline Module & 1744 & $40 / 2.29 \%$ & $6 / 2.10 \%$ \\
\hline Opto-board & 272 & $1 / 0.37 \%$ & $-/ 0.00 \%$ \\
\hline Cooling loop (high leak) & 88 & (3) / $0.00 \%$ & (0) / $0.00 \%$ \\
\hline Total dead pixels & & $\mathbf{3 . 0 1} \% / 8$ & $\mathbf{2 . 4 1} \%$ \\
\hline
\end{tabular}

Javier Bilbao 


\section{Pileup performance \& IBL}

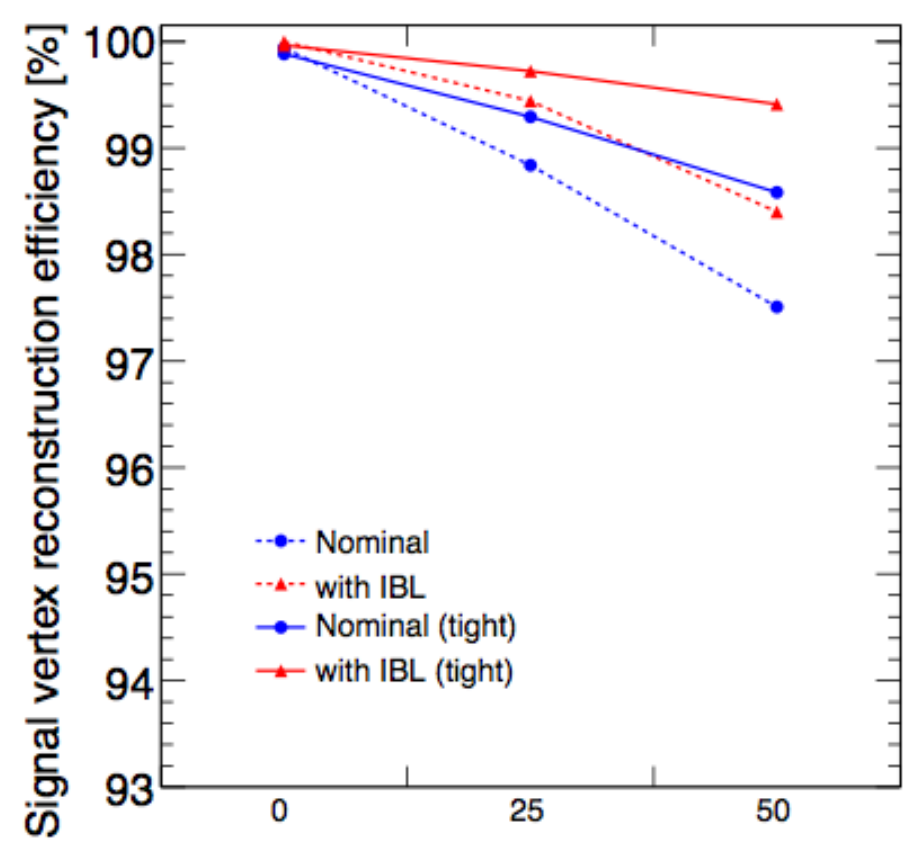

Average number of pileup interactions

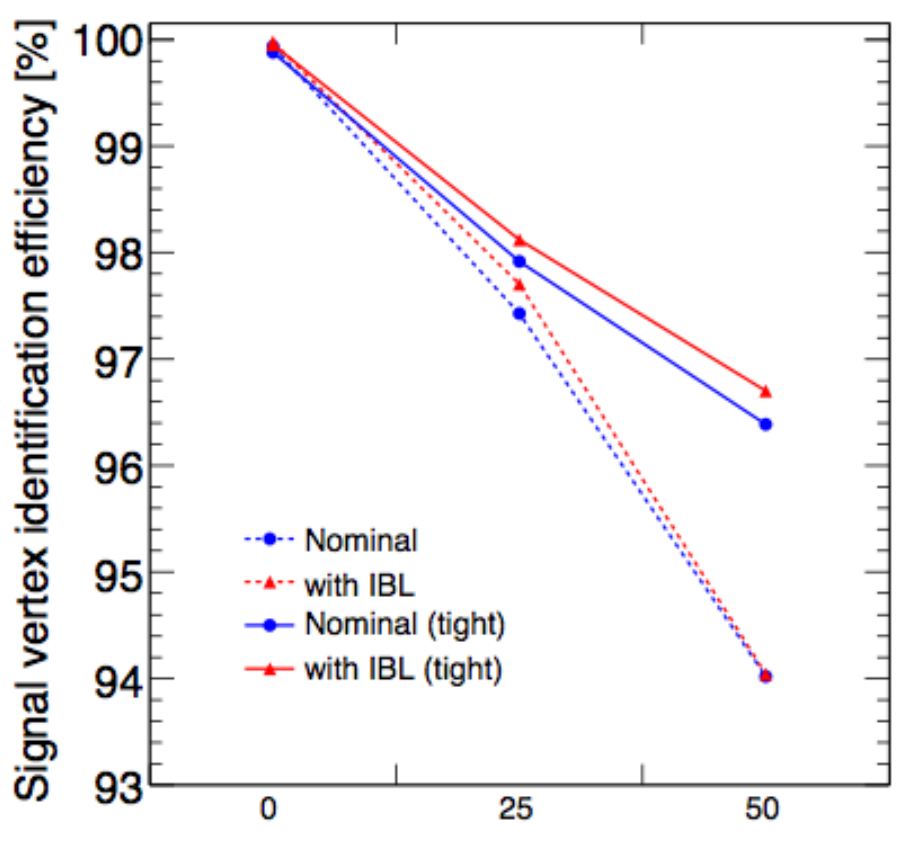

Average number of pileup interactions

Figure 31. Efficiency for reconstructing the primary vertex (right) in $t \bar{t}$ events as a function of the average number of pileup events for $t \bar{t}$ events. Shown are the results with and without IBL for $t \bar{t}$ events with the nominal and the high luminosity track selection. (left) efficiency to identify correctly the true primary vertex using the $\sum p_{T}^{2}$ algorithm.

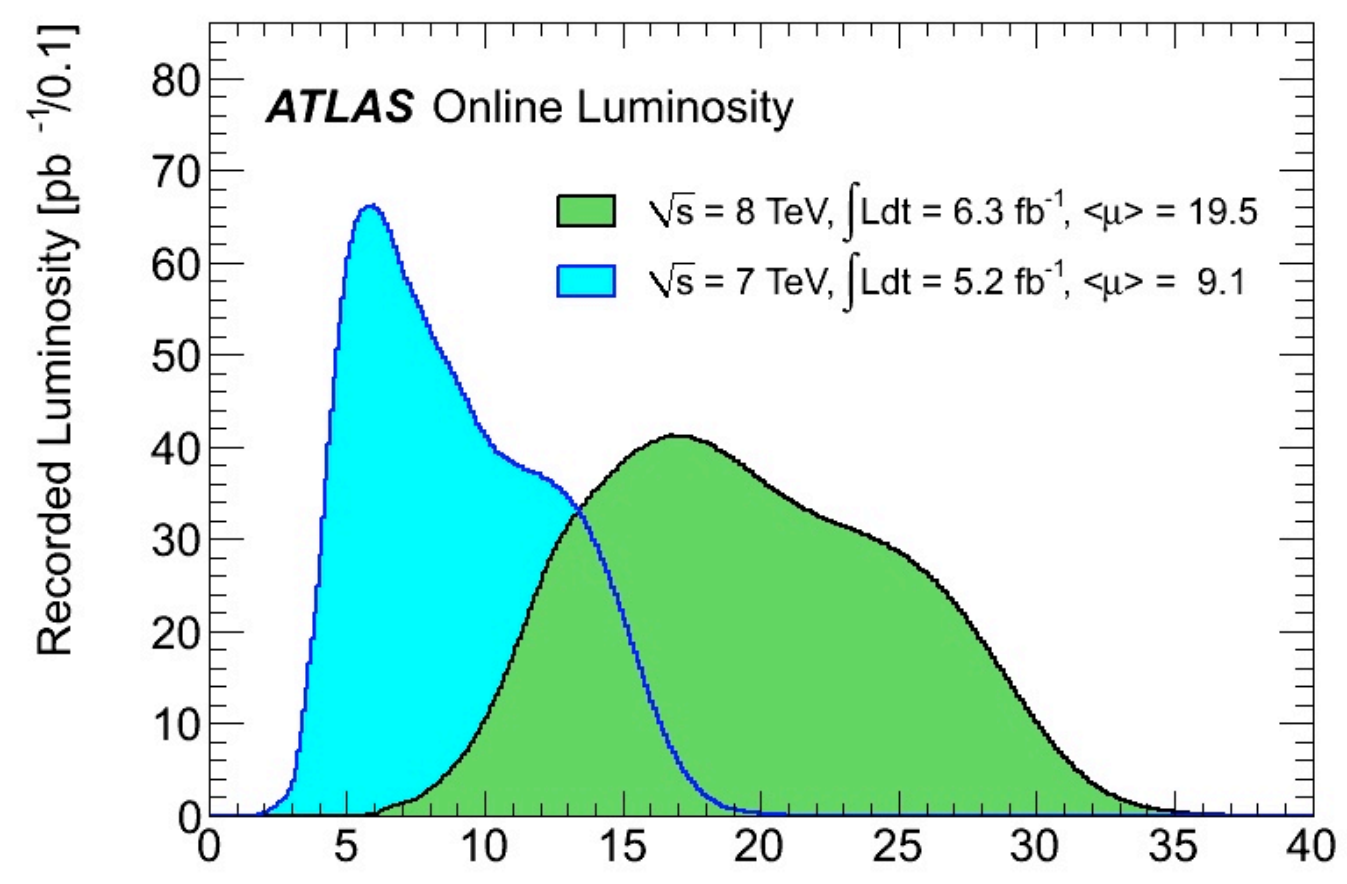

Javier Bilbao

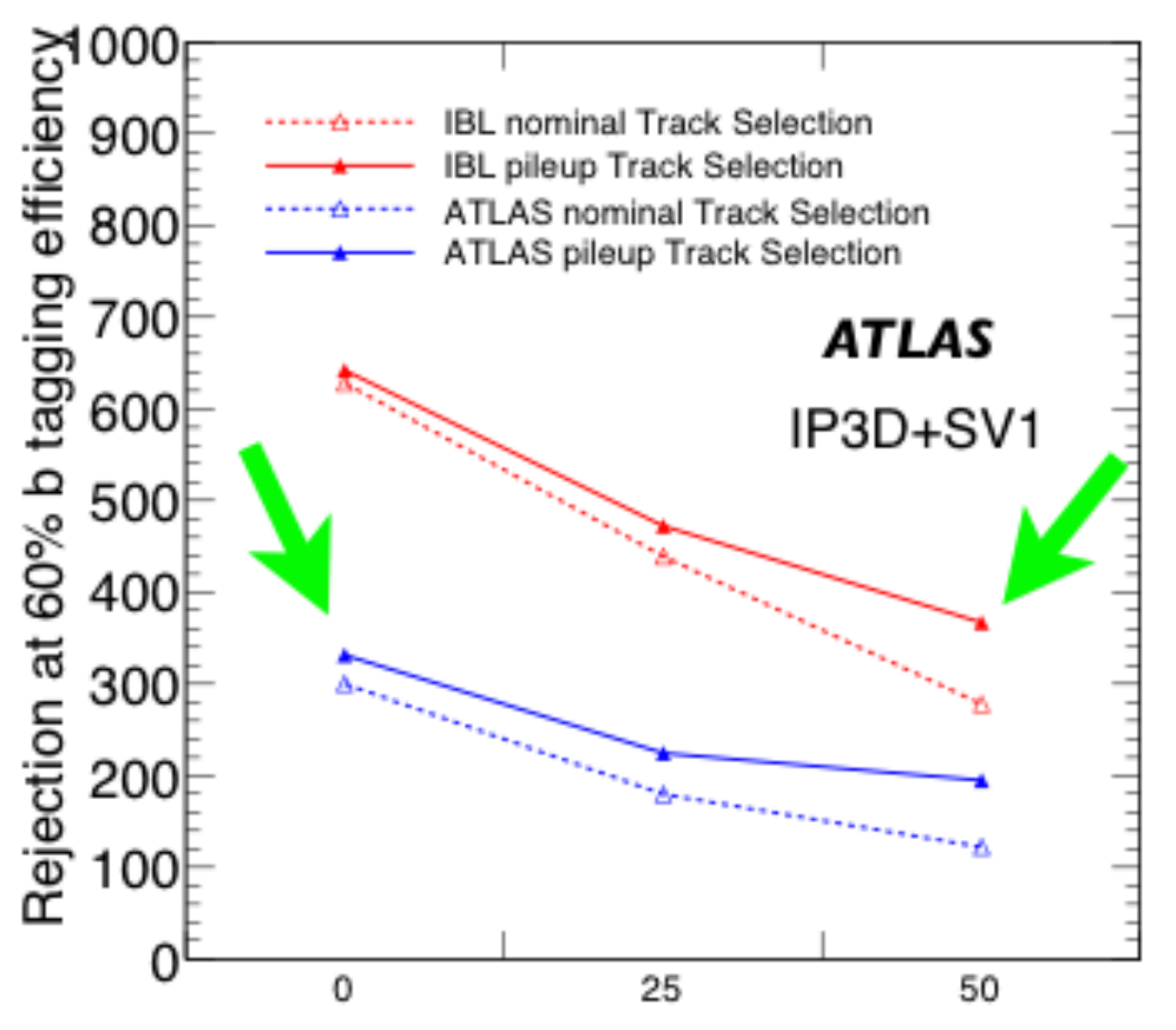

Number of pileup interactions 


\section{Module Qualification}

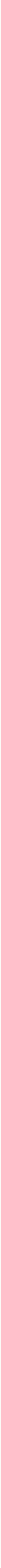




\section{Slim Edge}

Before (normal edge):

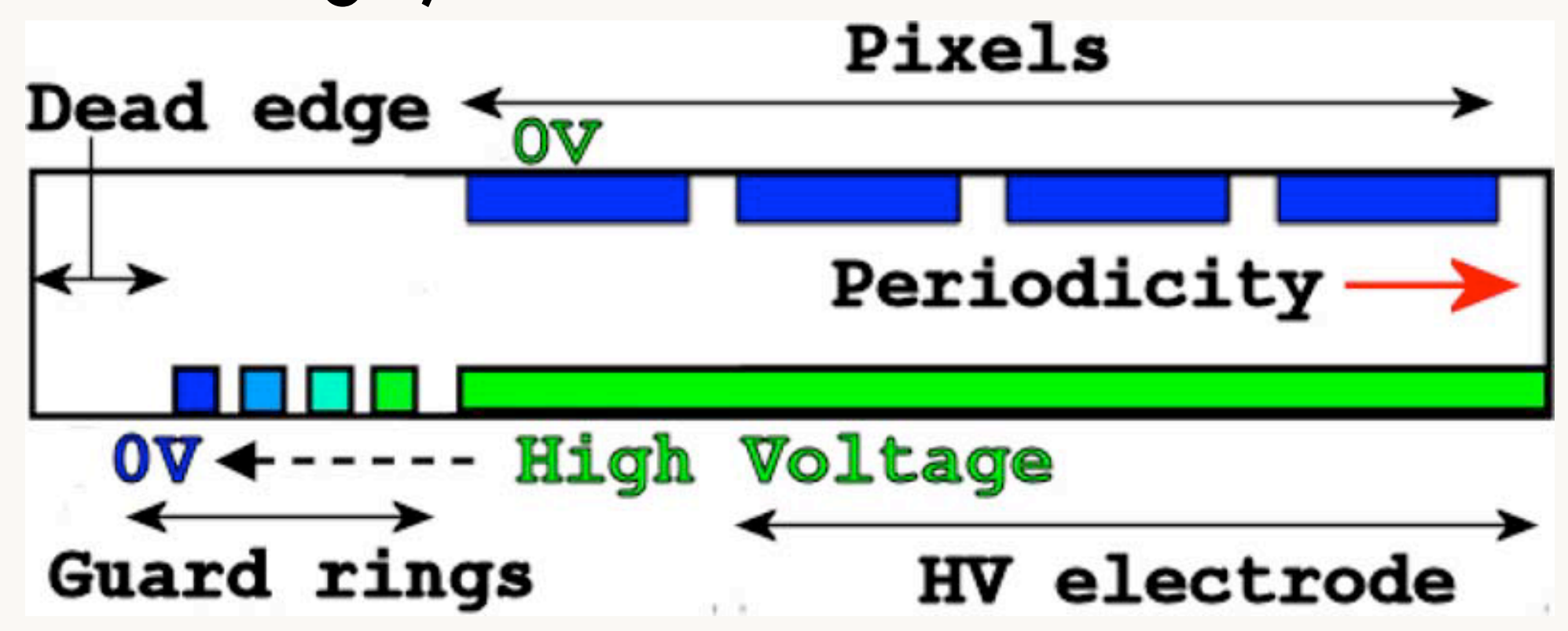

Slim-edge:

Alocated under the pixel matrix avoiding large edges

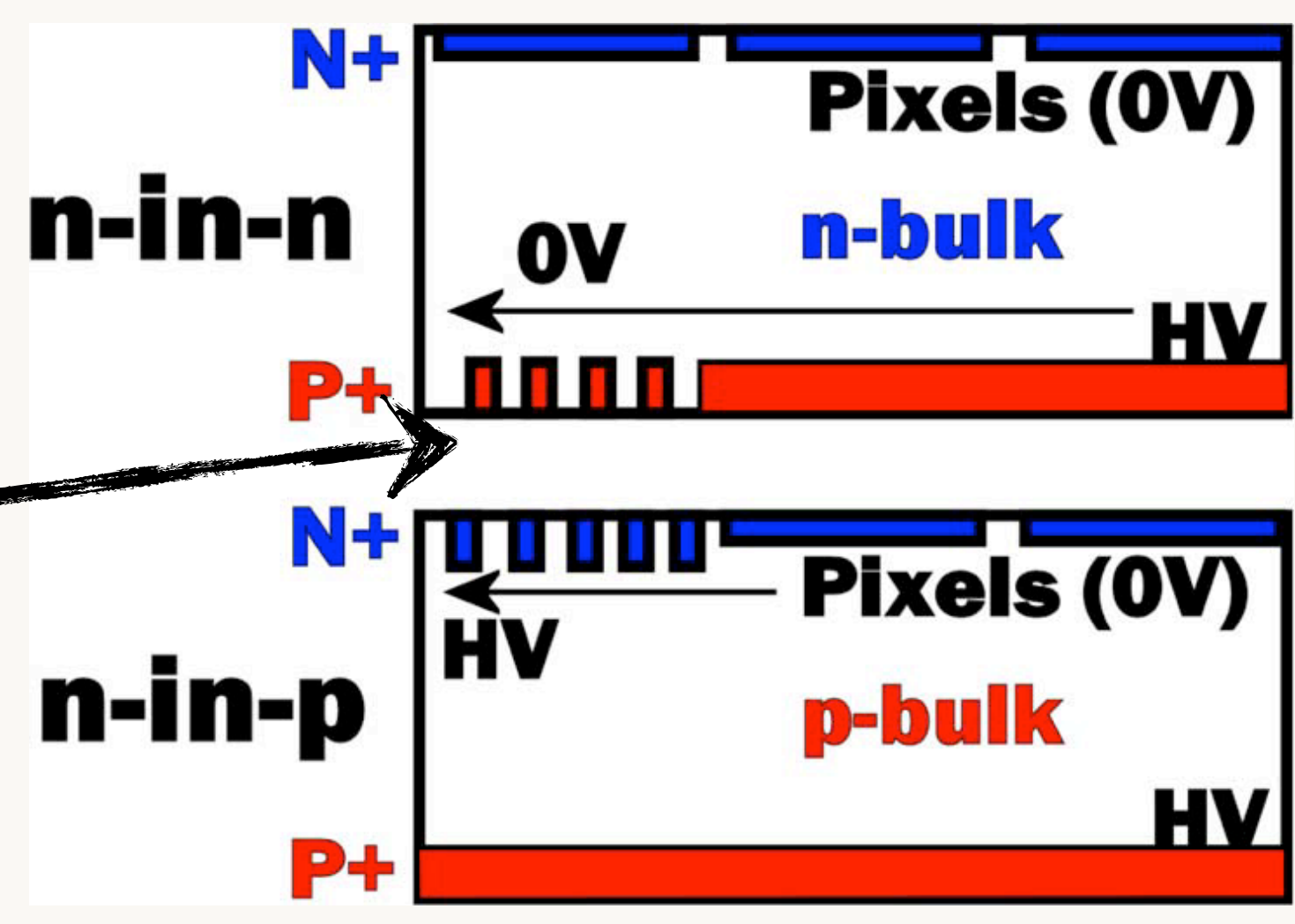




\section{IBL Cooling}

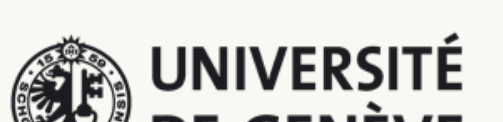
而3 DE GENĖVE

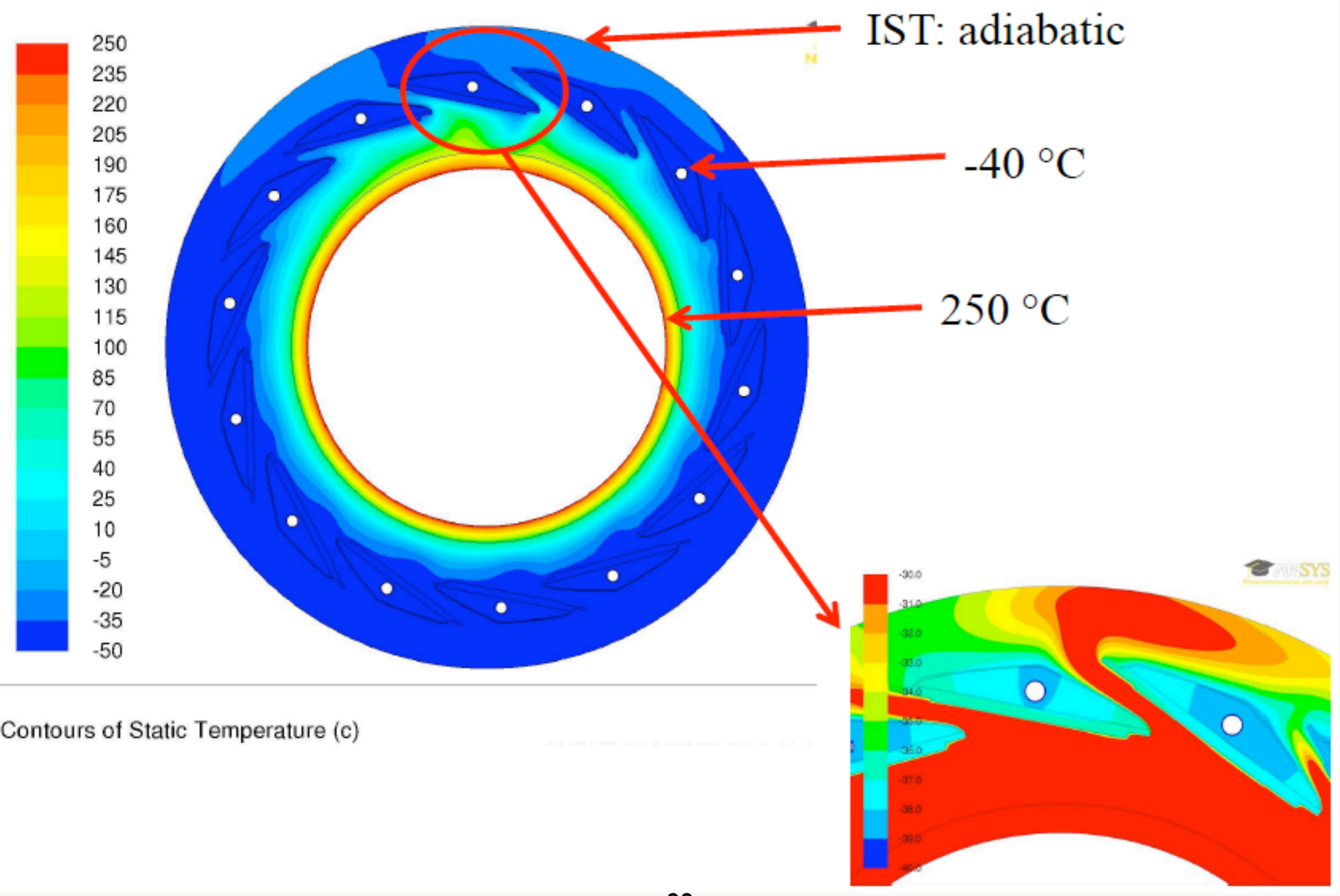




\section{IBL Cooling}

UNIVERSITÉ

10.2. DE GENĖVE
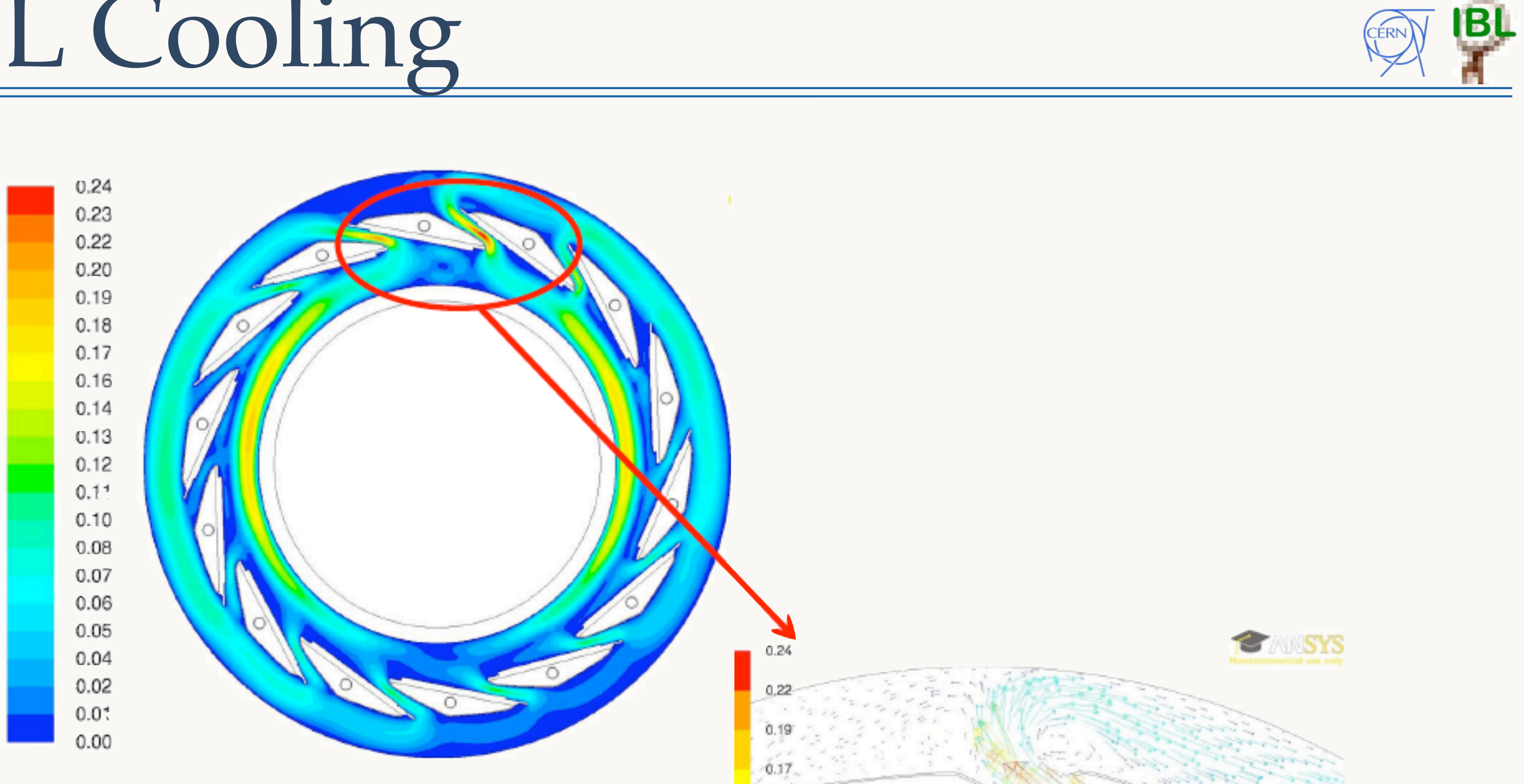

Contours of Velocitv Maanitude $(\mathrm{m} / \mathrm{s}$ )

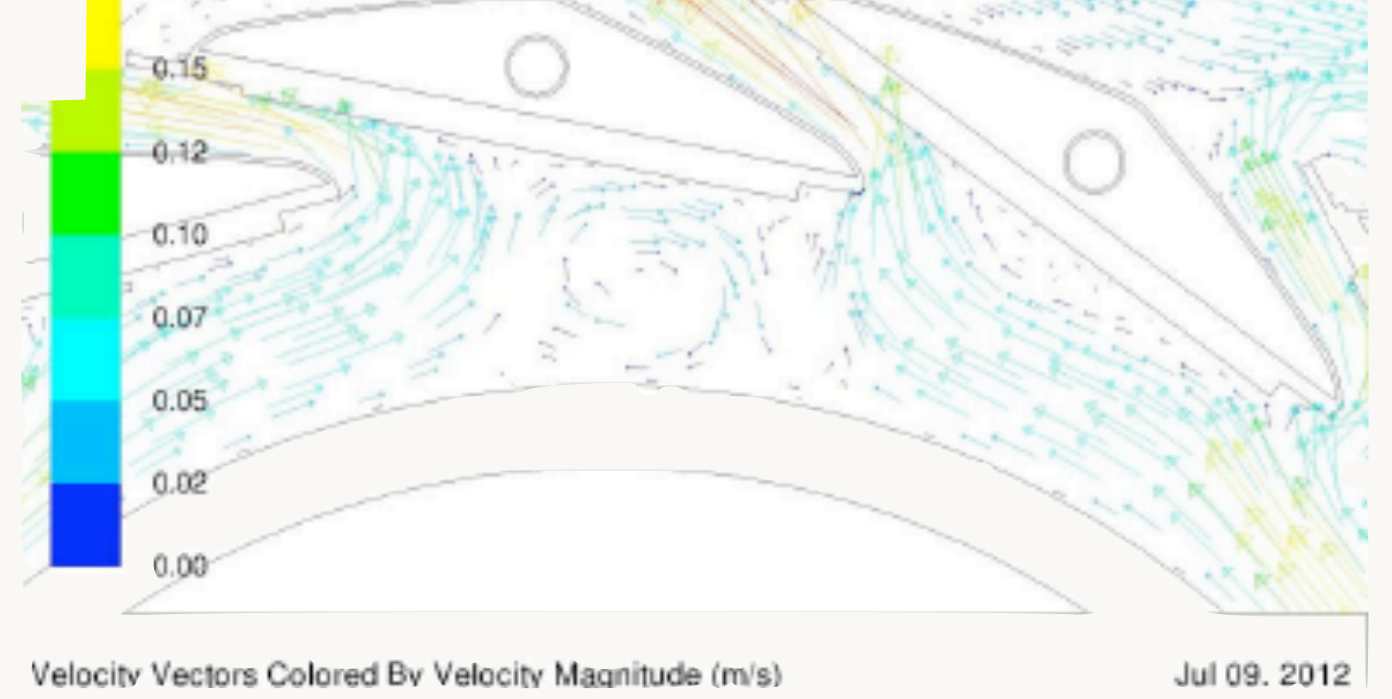




\section{Installation test}

\section{First full tests of beam pipe operation and IBL installation}

in end 2011:

Extraction of the Beam pipe and Insertion of the IST was performed on the scale of one mock up in building 180 . Some improvements under investigation...

\section{First tests with "soft" IST:}

Insertion test done with the Dummy IST from Composite Design as a first test - More "flexible" in term of overall bending compared to Seattle one. Next tests to be carried out with Final IST (with K13C fibres... Rigid but Brittle!)

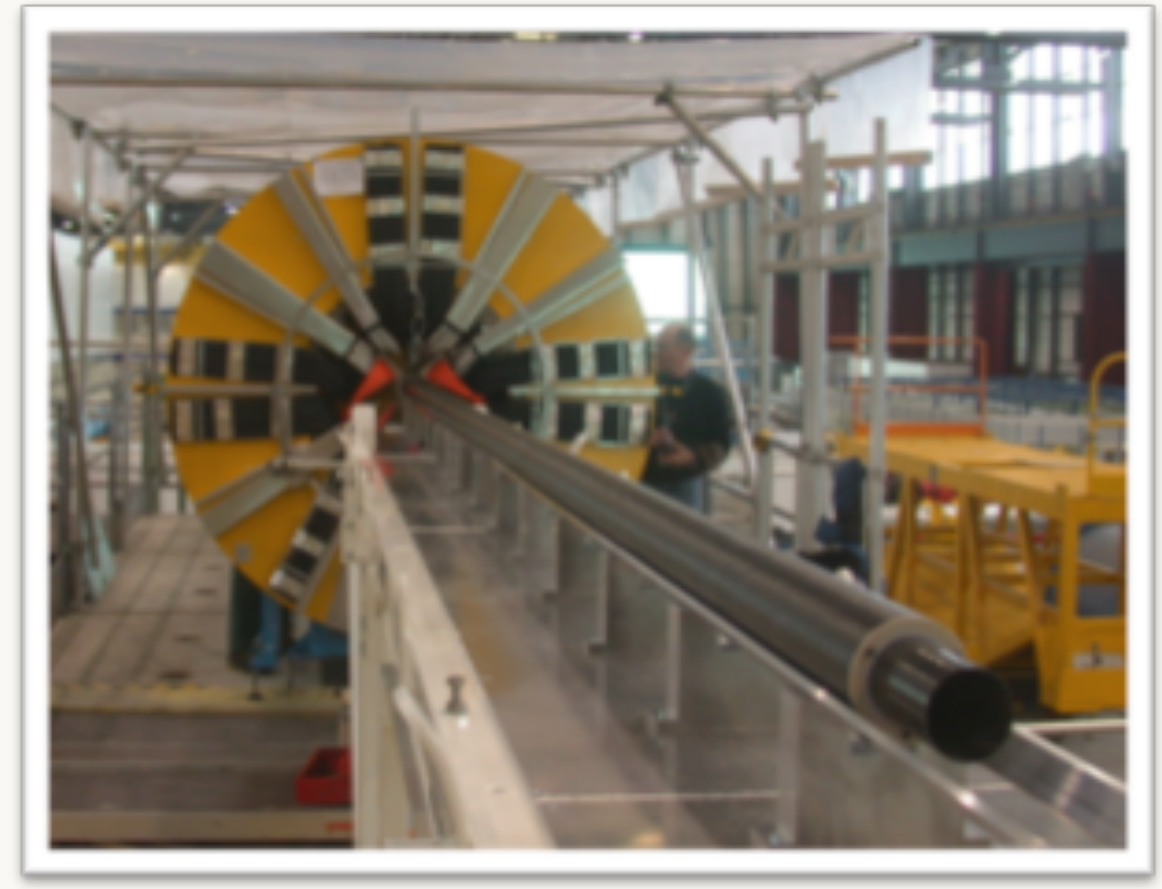

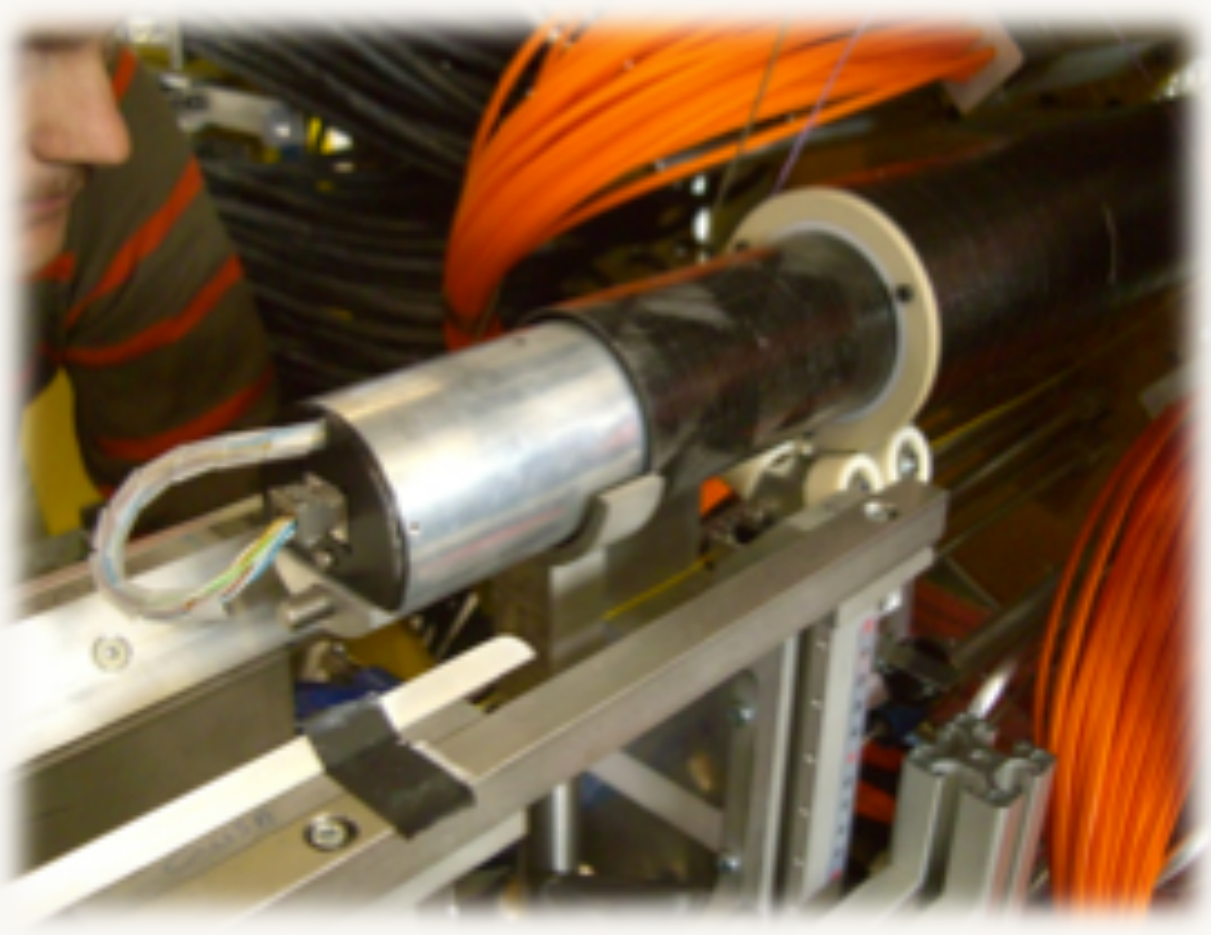

from: $\mathrm{H}$. Pernegger

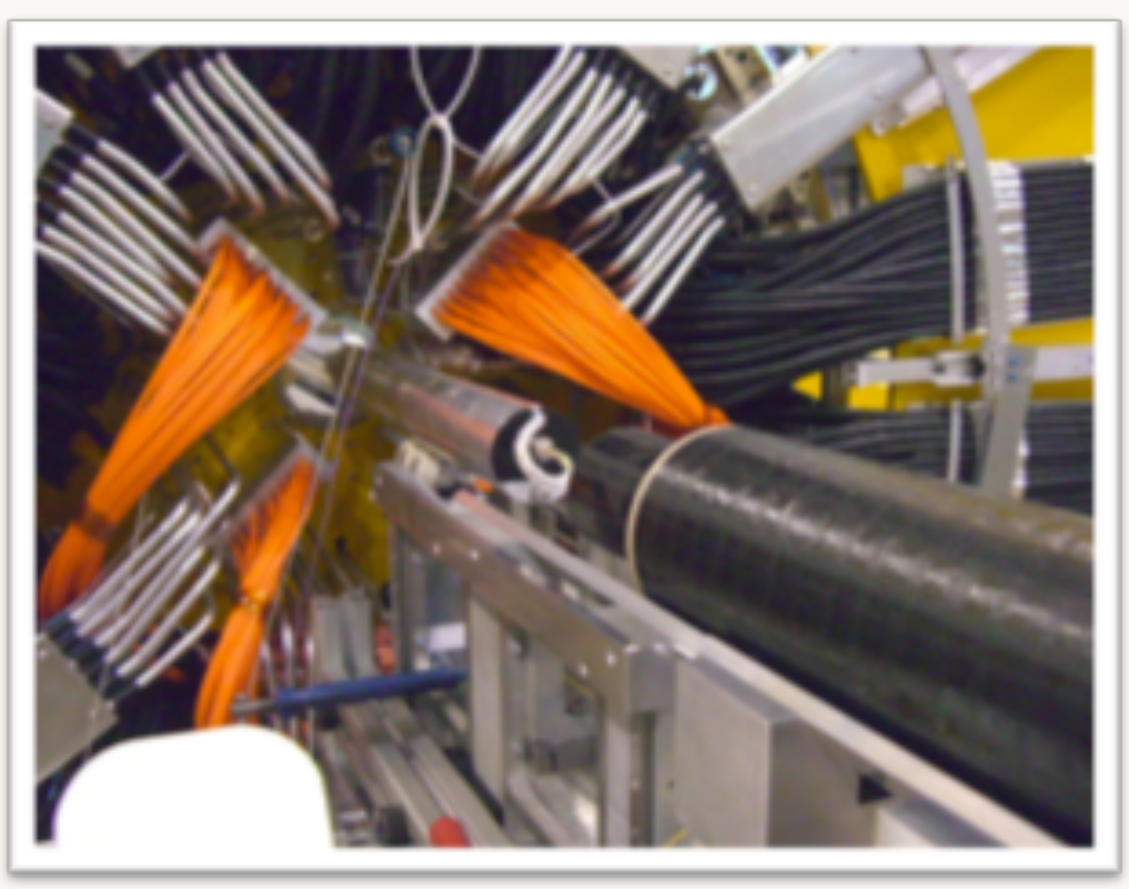

24 


\section{First Stave performance}

- Full stave load with FE-I4(A)

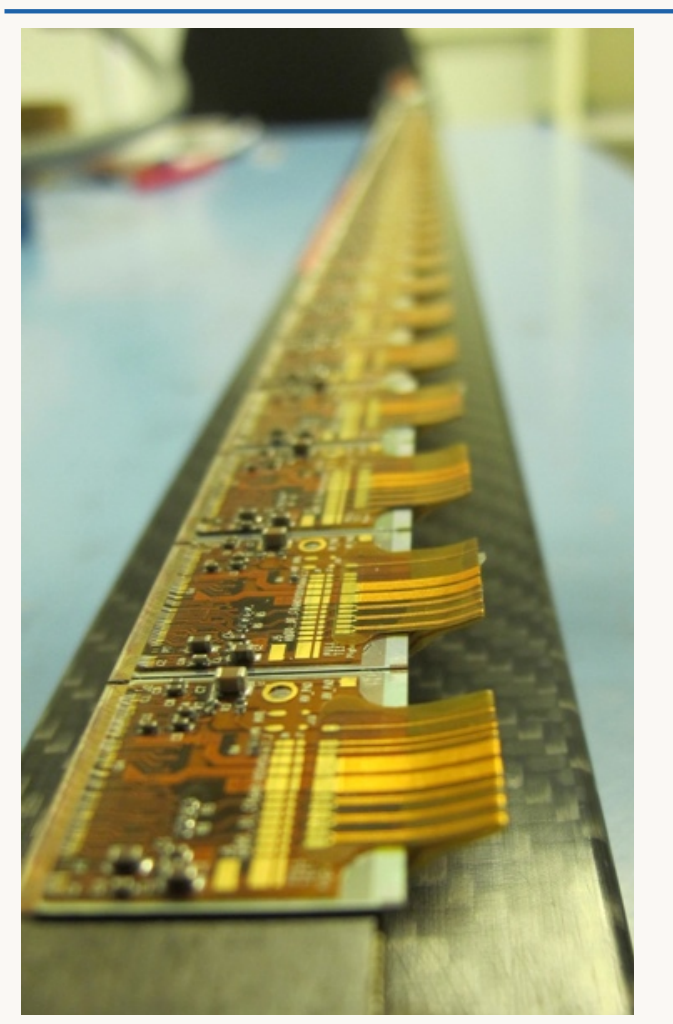

-Operation Voltage: -60V for planar sensor; -20V for 3D

- A-side good modules / C-side good (noisy pixels, disconected bumps, dead colum)

- Preproduction stave: test full production and read-out:

* Electrical test \& NTC read-out

粦 IV

* Analog \& Digital

* Threshold Scans

䊑 X-Talk

米 Source Scans

IV curves A
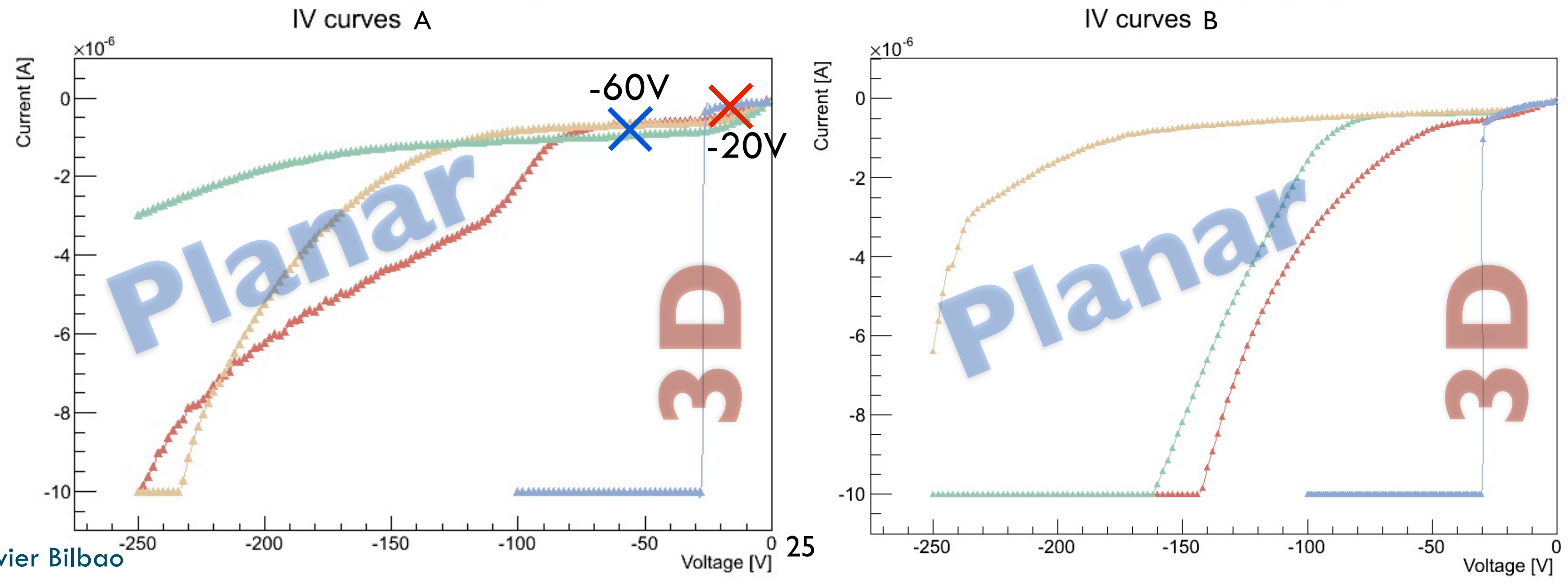


\section{Threshold Scan}

\section{C-side}

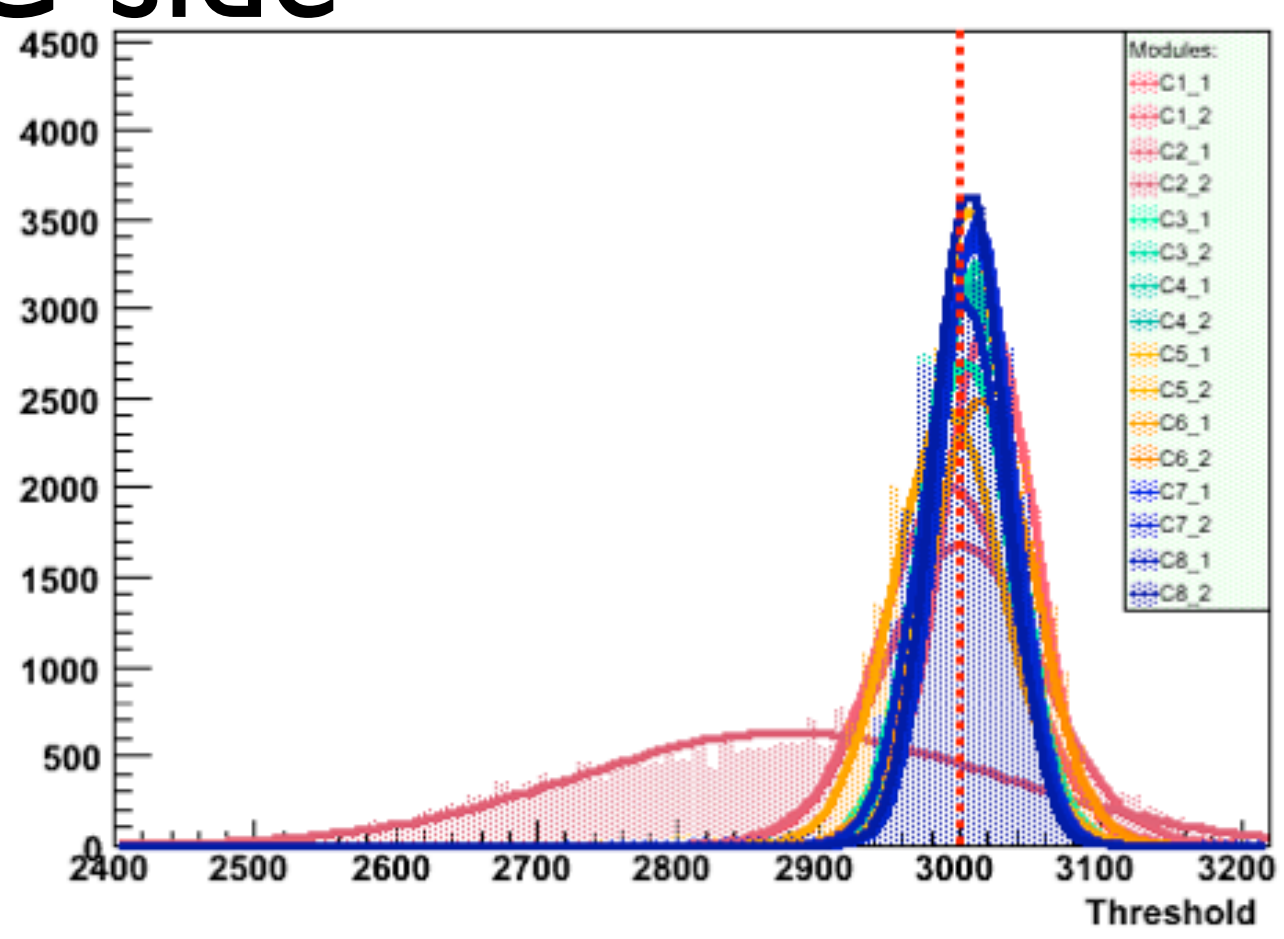

Threshold Mean Value

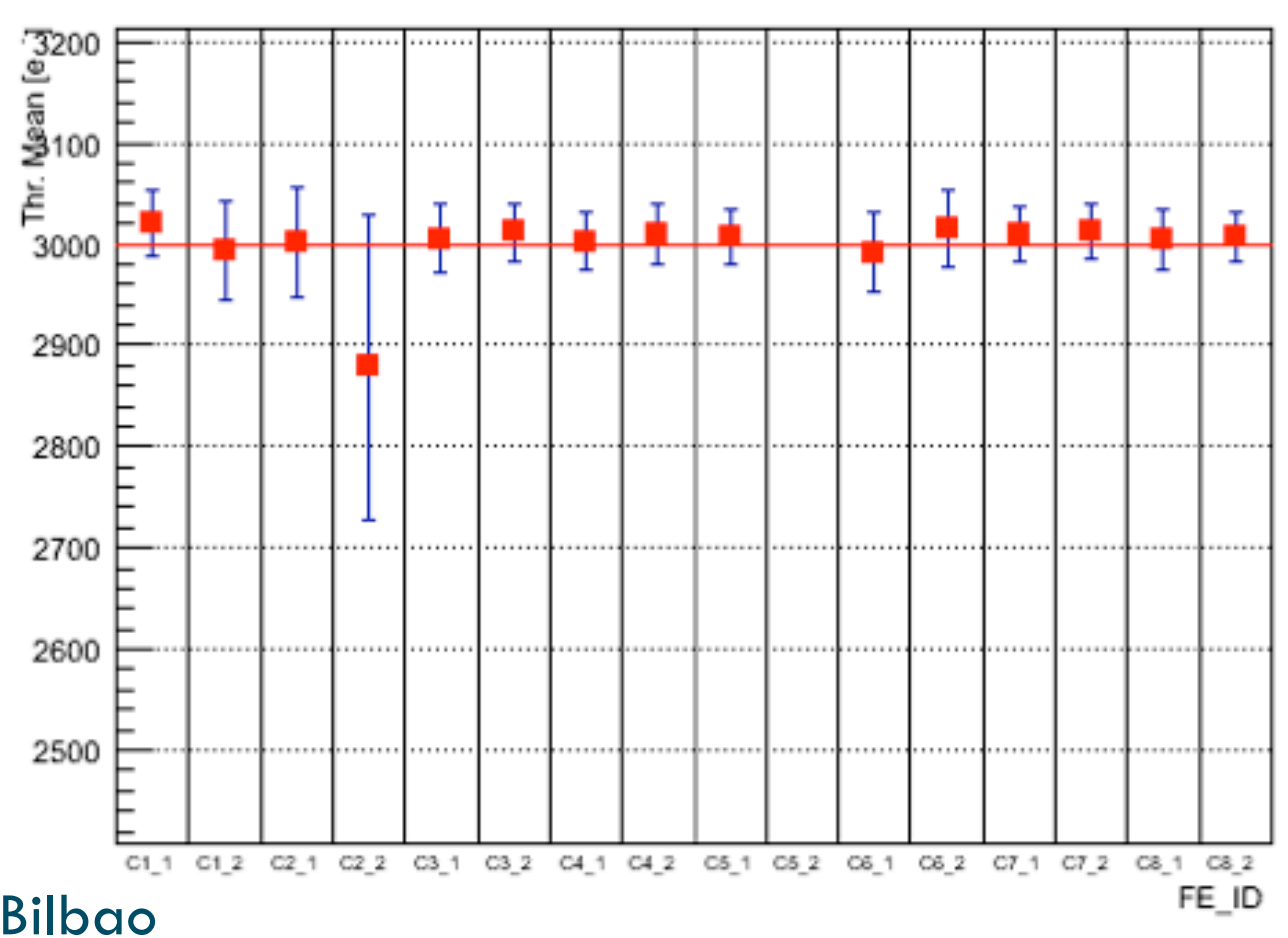

NOISE Distribution

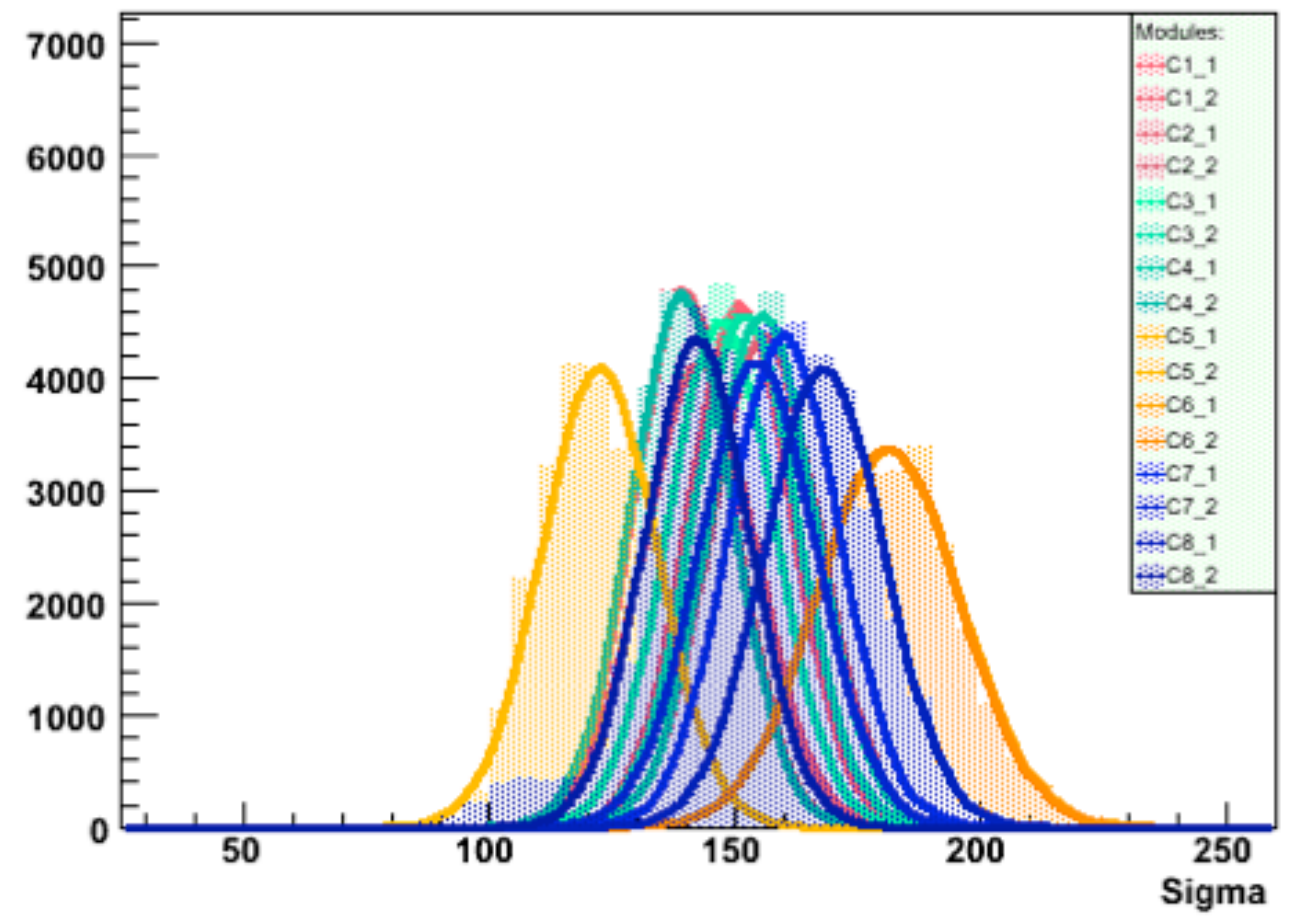

Sigma Mean Value

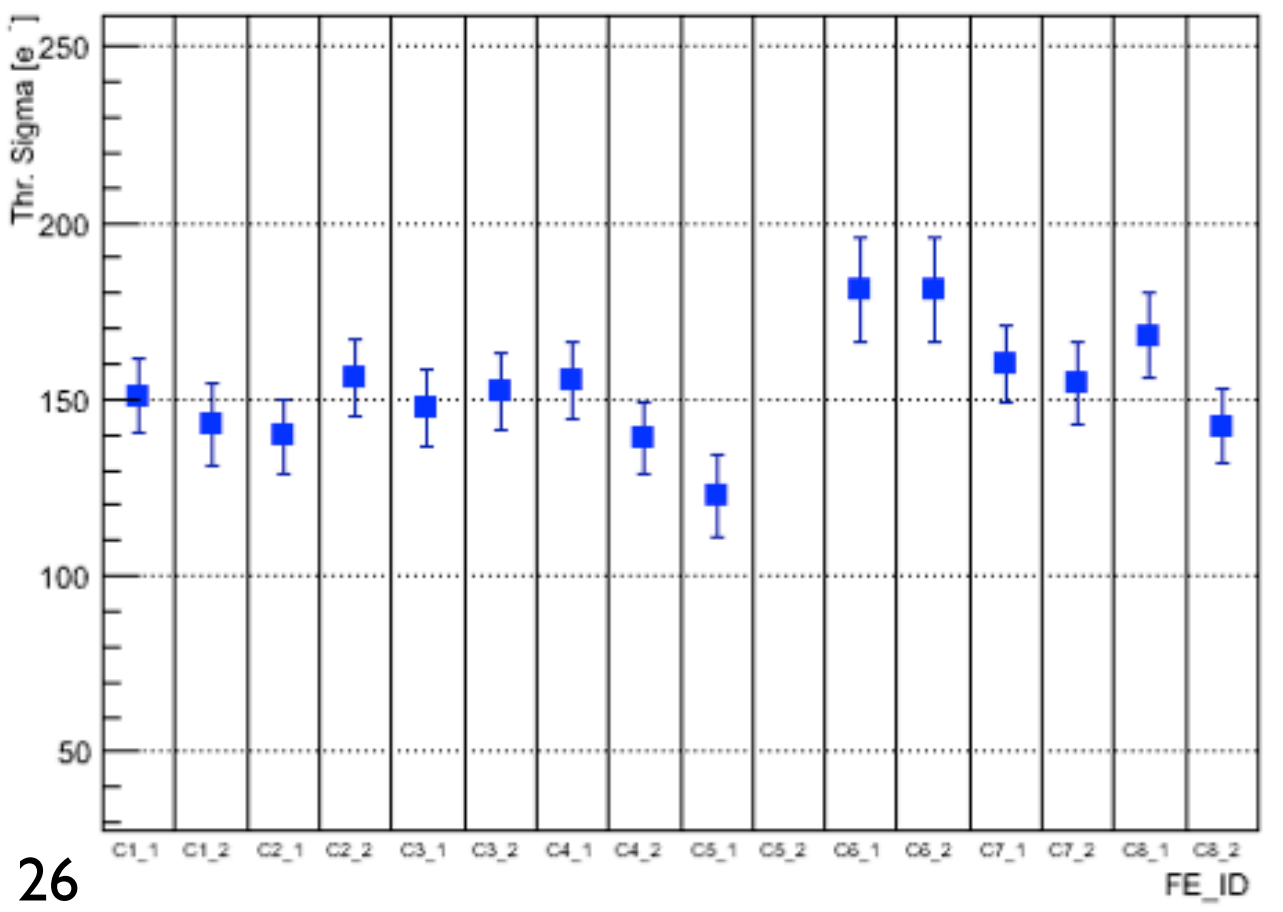




\section{Threshold Scan}

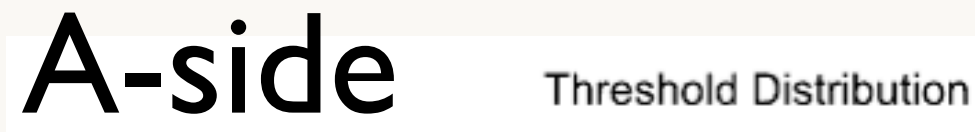

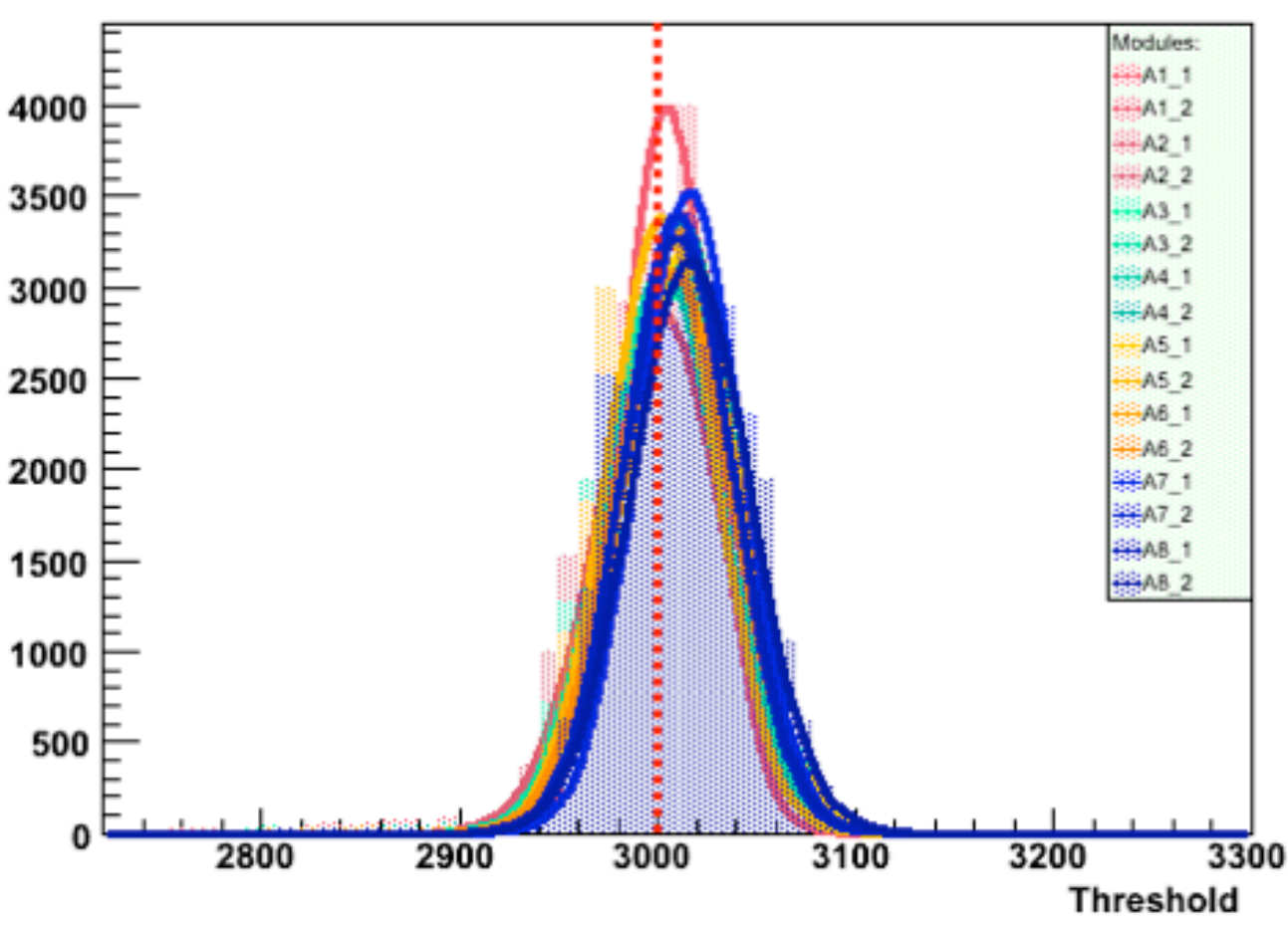

Threshold Mean Value

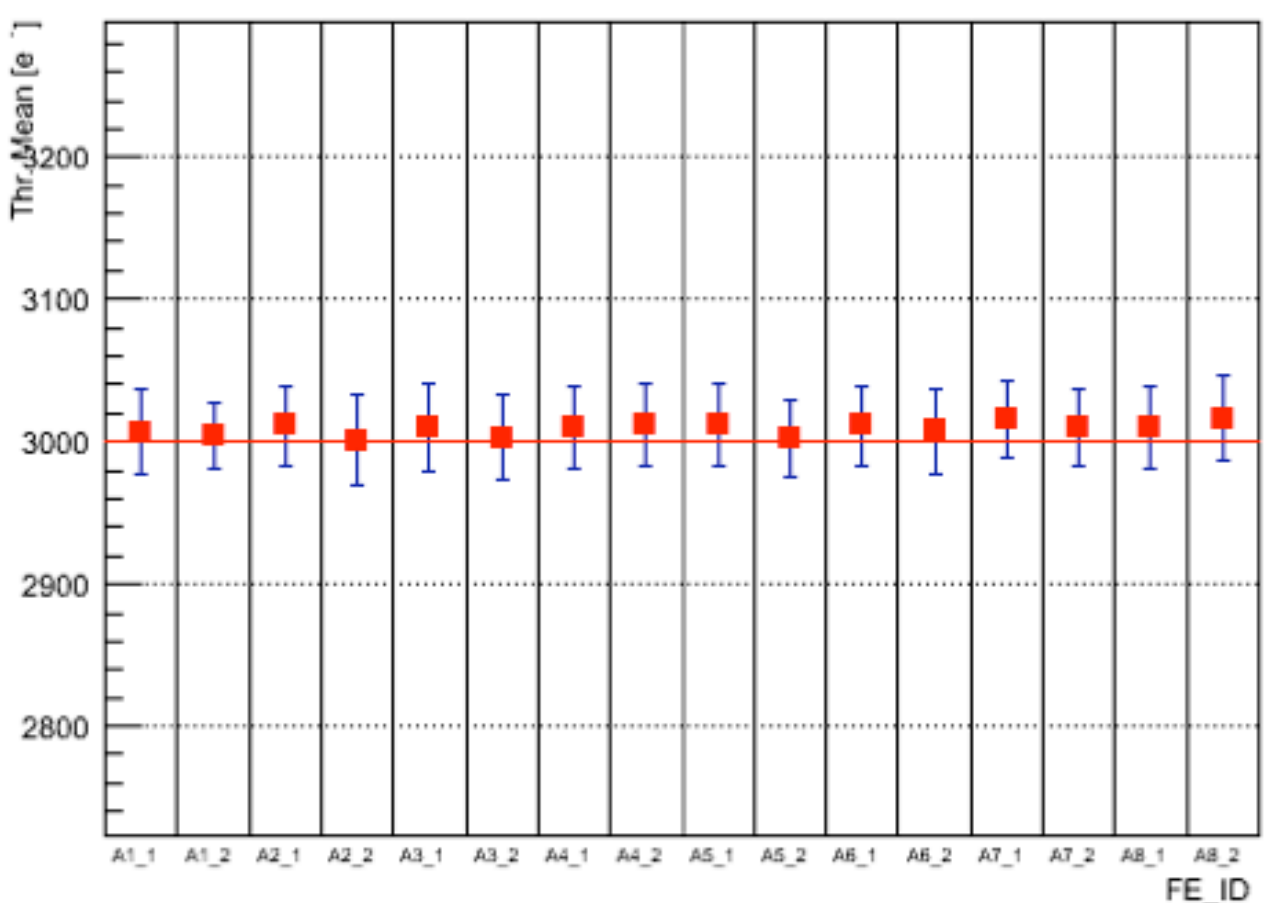

Javier Bilbao
NOISE Distribution

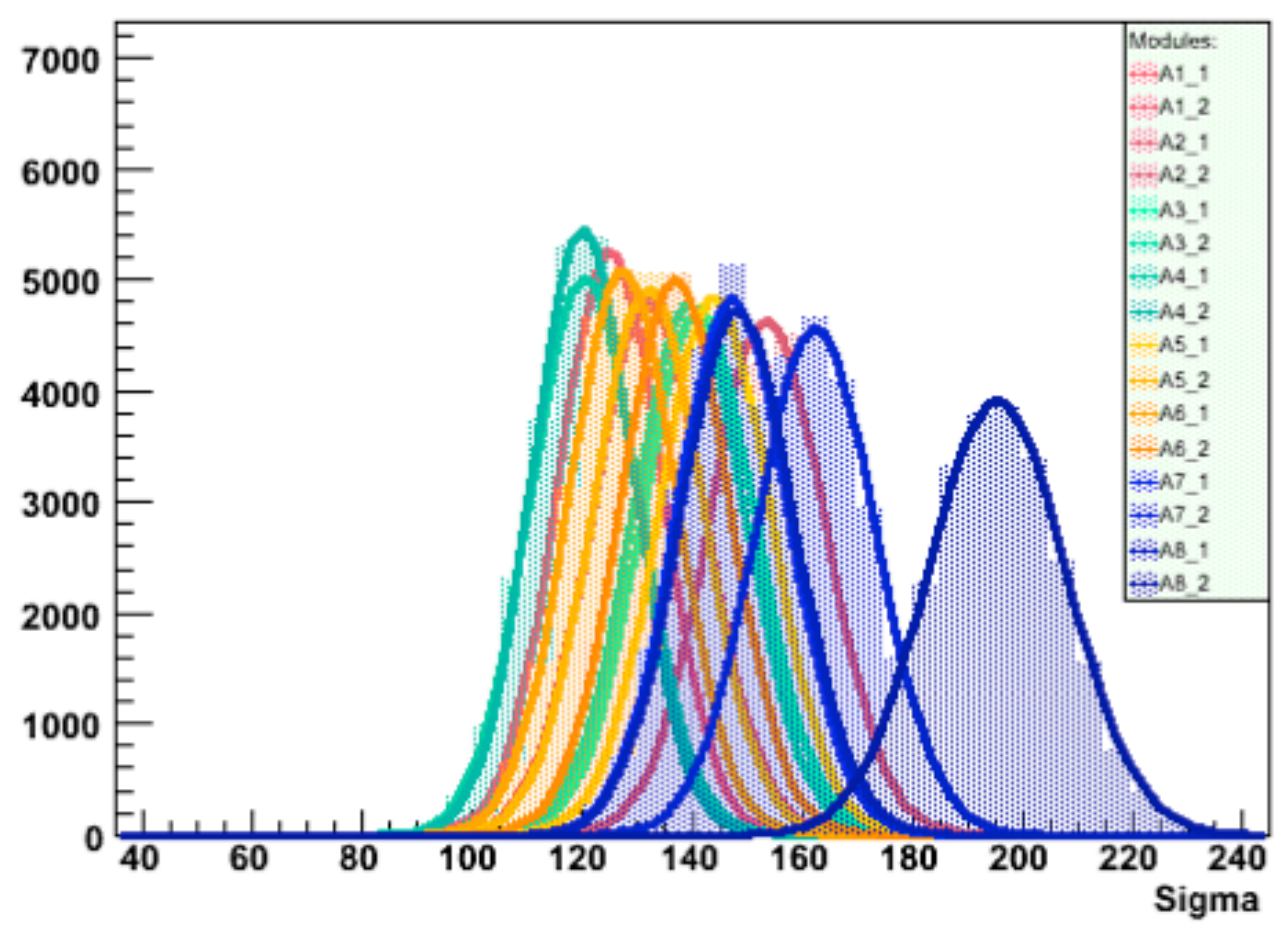

Sigma Mean Value

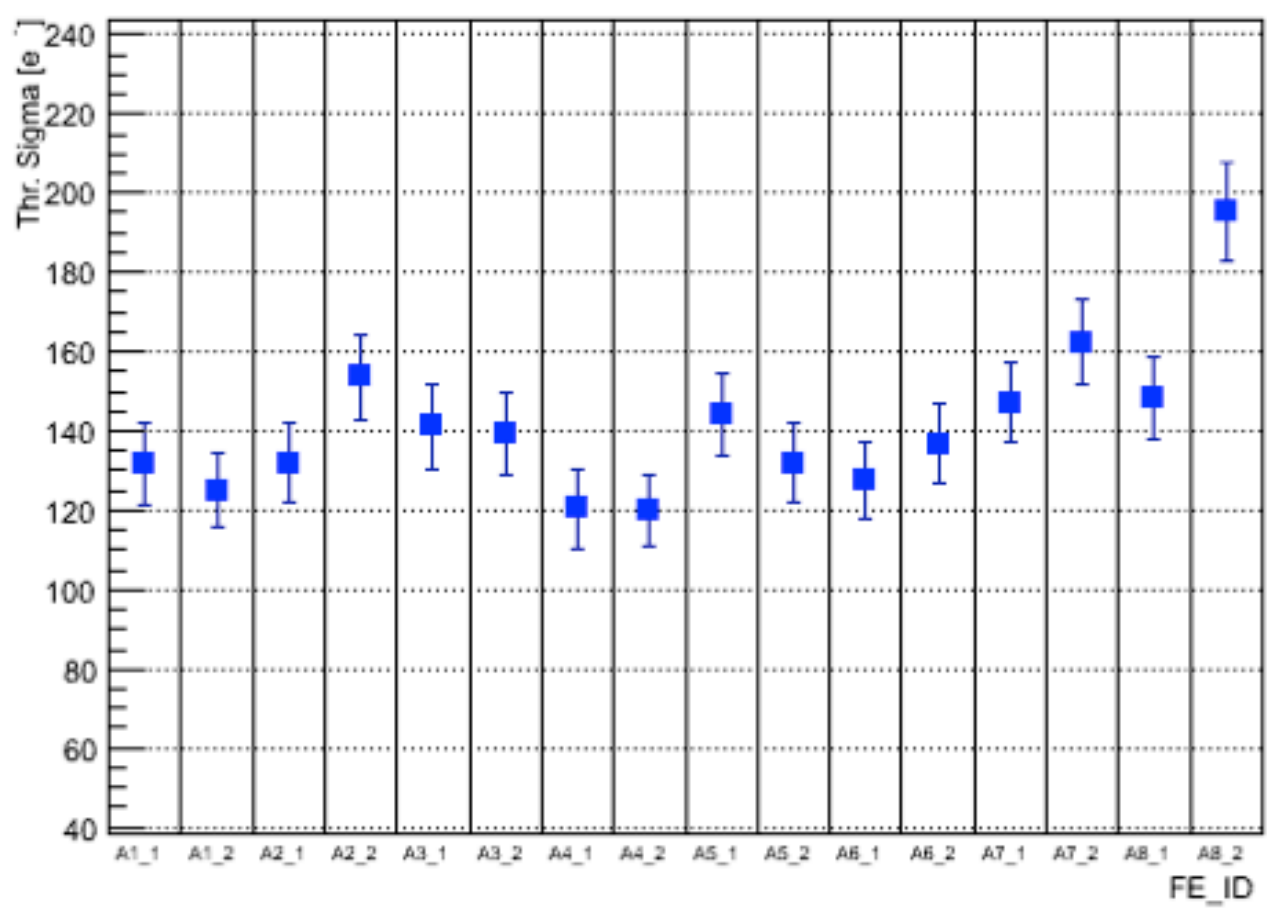

27 